\title{
Tropospheric sulfur simulation and sulfate direct radiative forcing in the Goddard Institute for Space Studies general circulation model
}

\section{Citation}

Koch, Dorothy, Daniel Jacob, Ina Tegen, David Rind, and Mian Chin. 1999. "Tropospheric Sulfur Simulation and Sulfate Direct Radiative Forcing in the Goddard Institute for Space Studies General Circulation Model." Journal of Geophysical Research 104 (D19): 23799. doi:10.1029/1999jd900248.

\section{Published Version}

doi:10.1029/1999JD900248

\section{Permanent link}

http://nrs.harvard.edu/urn-3:HUL.InstRepos:14121826

\section{Terms of Use}

This article was downloaded from Harvard University's DASH repository, and is made available under the terms and conditions applicable to Other Posted Material, as set forth at http:// nrs.harvard.edu/urn-3:HUL.InstRepos:dash.current.terms-of-use\#LAA

\section{Share Your Story}

The Harvard community has made this article openly available.

Please share how this access benefits you. Submit a story.

\section{Accessibility}




\title{
Tropospheric sulfur simulation and sulfate direct radiative forcing in the Goddard Institute for Space Studies general circulation model
}

\author{
Dorothy Koch, ${ }^{1}$ Daniel Jacob, ${ }^{2}$ Ina Tegen, ${ }^{1}$ David Rind, ${ }^{1}$ \\ and Mian Chin ${ }^{3,4}$
}

\begin{abstract}
Global simulations of tropospheric sulfur are performed in the Goddard Institute for Space Studies (GISS) general circulation model (GCM) and used to calculate anthropogenic sulfate direct radiative forcing. Prognostic species are incloud oxidant $\mathrm{H}_{2} \mathrm{O}_{2}$, dimethylsulfide (DMS), methanesulfonic acid (MSA), $\mathrm{SO}_{2}$ and sulfate. Compared with most previous models (except others with prognostic $\mathrm{H}_{2} \mathrm{O}_{2}$ ), this model has relatively high anthropogenic $\mathrm{SO}_{2}$ and sulfate burden. We show that this is due partly to the depletion of the prognostic $\mathrm{H}_{2} \mathrm{O}_{2}$ and that moist convection delivers significant levels of $\mathrm{SO}_{2}$ to the free troposphere in polluted regions. Model agreement with surface observations is not remarkably different from previous studies. Following some previous studies, we propose that an additional in-cloud or heterogeneous oxidant is likely to improve the simulation near the surface. Our DMS source is lower than sources in previous studies, and sulfur values in remote regions are generally lower than those observed. Because of the high flux of $\mathrm{SO}_{2}$ to the free troposphere and the relatively low natural source, our model indicates a larger global anthropogenic contribution to the sulfate burden (77\%) than was estimated by previous global models. Additional high-altitude observations of the sulfur species are needed for model validation and resolution of this issue. Direct radiative forcing calculations give an annual average anthropogenic sulfate forcing of $-0.67 \mathrm{~W} / \mathrm{m}^{2}$. We compare the radiative forcings due to online (hourly varying) versus offline (monthly average) sulfate and find little difference on a global average, but we do find differences as great as $10 \%$ in some regions. Thus, for example, over some polluted continental regions the forcing due to offline sulfate exceeds that of online sulfate, while over some oceanic regions the online sulfate forcing is larger. We show that these patterns are probably related to the correlation between clouds and sulfate, with positive correlations occuring over some polluted continental regions and negative correlations over high-latitude oceanic regions.
\end{abstract}

\section{Introduction}

Anthropogenic sulfate is believed to have a significant effect on planetary radiation and climate and may also play an important role as a locus for heterogeneous chemical reactions. Estimates of anthropogenic

\footnotetext{
${ }^{1}$ NASA Goddard Institute for Space Studies, Columbia University, New York.

${ }^{2}$ Department of Earth and Planetary Sciences, Harvard University, Cambridge, Massachusetts.

${ }^{3}$ School of Earth and Atmospheric Sciences, Georgia Institute of Technology, Atlanta. land.

${ }^{4}$ NASA Goddard Space Flight Center, Greenbelt, Mary-

Copyright 1999 by the American Geophysical Union.

Paper number 1999JD900248.

0148-0227/99/1999JD900248\$09.00
}

sulfate direct radiative forcing range from -0.3 to -0.9 $\mathrm{W} / \mathrm{m}^{2}$, which may be insufficient to counteract the global warming of greenhouse gases in models to the extent required by observed surface temperature changes. While sulfate alone may have a small direct effect, the total forcing from all aerosol species is likely to be significant. Sulfur also interacts with other aerosol types, for example by increasing the solubility of otherwise hygrophobic particles. The behavior of these internally and externally mixed aerosol types is an area of increasing interest and importance. Another such area is the effect of anthropogenic sulfate on cloud radiative properties, or the aerosol "indirect effect": as an increasing sulfate particle population act as cloud condensation nuclei, cloud reflectivity and persistance increase. Although poorly understood, this indirect effect may be more significant than the direct effect.

These various ways in which sulfate may have important effects on climate and atmospheric chemistry 
require that increasingly sophisticated chemical treatments be used in the simulations. In order to assess these treatments, ongoing careful comparison of model output with observations is required.

Probably the most complex and poorly understood aspect of sulfate modeling is the simulation of in-cloud oxidation of $\mathrm{SO}_{2}$ to form sulfate. Proper simulation of this largest source of sulfate is important, since it is ultimately desirable to allow the sulfate particles to affect cloud properties; thus we require cloud production and removal of sulfate by precipitation to be as accurate as possible. In-cloud oxidation simulation methods are becoming more complex. Early models used fixed oxidation rates and climatological cloud statistics to calculate sulfate generation [Langner and Rodhe, 1991; Pham et al., 1995]. Chin et al. [1996] used off-line oxidant $\mathrm{H}_{2} \mathrm{O}_{2}$ fields, and assumed complete reaction of $\mathrm{SO}_{2}$ and $\mathrm{H}_{2} \mathrm{O}_{2}$ to form sulfate. Feichter et al. [1996] also used offline $\mathrm{H}_{2} \mathrm{O}_{2}$ and $\mathrm{O}_{3}$, but sulfate production was limited by a reaction rate and dissolution of gases was determined by Henry's law solubility. A problem with using offline oxidant fields is that the oxidant is then assumed to be regenerated in the next time step, which could result in excessive oxidation, since $\mathrm{H}_{2} \mathrm{O}_{2}$ has a lifetime of 1 to 2 days. Our model includes prognostic $\mathrm{H}_{2} \mathrm{O}_{2}$. Lelieveld et al. [1997] and Roelofs et al. [1998] included both $\mathrm{H}_{2} \mathrm{O}_{2}$ and $\mathrm{O}_{3}$ as prognostic oxidants. We will compare our results with these previous models. We will also explore the importance of using prognostic $\mathrm{H}_{2} \mathrm{O}_{2}$ by comparing results with those from a run having fixed $\mathrm{H}_{2} \mathrm{O}_{2}$ fields.

Another area of interest is to use the model to explore the contribution of anthropogenic and natural sulfate sources to the sulfate burden. In the previous studies of Chin and Jacob [1996] and Feichter et al. [1997], the natural component was found to be $60 \%$ and $44 \%$ (globally), respectively. It is often assumed that at remote oceanic regions, most of the sulfate is derived from natural sources. Model results from Chin and Jacob [1996] indicated that over $80 \%$ of the sulfate burden over much of the Pacific Ocean is derived from a natural source. Thornton et al. [1997] found that at high altitudes (> $8.5 \mathrm{~km}$ ) over the Pacific, less than $10 \%$ of the $\mathrm{SO}_{2}$ was derived from DMS; at lower levels over the oceans, the contribution is undoubtedly greater. This issue remains unresolved.

Along with our effort to improve in-cloud oxidation and scavenging processes, we are also interested in exploring the relationship between sulfate and clouds, due to the in-cloud production of sulfate by clouds and to the precipitation scavenging of sulfate by clouds. If the former effect is dominant, we would expect a positive correlation to exist between clouds and sulfate. We expect positive correlation between clouds and sulfate to reduce the sulfate direct radiative effect, since the clouds would have a dominant radiative effect. Sulfate would have a more important radiative effect if it is anticorrelated with clouds, as might be expected if precipitation scavenging controls the cloud-sulfate relation.
As was noted above, there is a substantial range in estimates of the direct radiative effect of sulfate aerosols. The strength of the forcing depends upon a number of factors and model assumptions, including the sulfate burden and distribution, the formulation of optical thickness and how it depends on relative humidity, choice of optical parameters, radiative transfer scheme, and other model climate features such as cloud cover. Since the current study focuses on sulfate mass transport, we are particularly interested in discerning the influence of the sulfate distribution on radiative forcing. We will also examine the differences between using online and off-line sulfate to calculate forcing. Ferchter et al. [1997] found a very small difference between off-line and on-line sulfate forcings on a global average for the direct radiative forcing, but a large overestimate of forcing $(20 \%)$ by offline sulfate for indirect forcing. We will revisit this issue, since most previous radiative calculations and all climate studies have used offline sulfate.

\section{Model Description}

The prognostic species $\mathrm{SO}_{2}$, sulfate, $\mathrm{H}_{2} \mathrm{O}_{2}$, dimethylsulfide (DMS) and methanesulfonic acid (MSA) are run on-line (i.e. respond immediately to model processes) in the Goddard Institute for Space Studies (GISS) general circulation model (GCM) II-prime. Model resolution is $4^{\circ}$ latitude by $5^{\circ}$ longitude and 9 vertical sigma layers, with 1 to 2 layers in the stratosphere. The model uses climatological fixed sea surface temperatures. In comparison with the older version of the GISS GCM [Hansen et al., 1983] this version has improved subroutines for the boundary layer, convection, land surface, and a cloud liquid water budget, and uses the quadratic upstream scheme for heat and moisture advection as well as a fourth-order advection scheme. Details on the various components are discussed or referenced by Rind and Lerner [1996]. Chemical species are also transported using a quadratic upstream scheme. The radon 222 simulation of Rind and Lerner [1996] indicates reduction of tropical convective transport compared with the previous version of the GISS GCM.

\subsection{Sources}

Sources of $\mathrm{SO}_{2}$ and DMS are listed in Table 1. The anthropogenic emissions include the seasonally varying emissions of fossil fuel combustion and industrial activities compiled by the Global Emissions Inventory Activity (GEIA). We assume that $3 \%$ of this is emitted as sulfate, the rest as $\mathrm{SO}_{2}$. Other anthropogenic sources include biomass burning and an aircraft source.

The natural sources include a non-eruptive volcanic source and DMS. The volcanic source is implemented following Chin et al. [1996]. We do not include eruptive volcanoes because we wish to validate the model against long-term averages of observations, which span a variety of years. The DMS source is based on DMS sea-surface concentration data from Kettle et al. [1999]. 
Table 1. Global Sulfur Emissions

\begin{tabular}{llrl}
\hline Species & \multicolumn{1}{c}{ Source } & Emissions, Tg S/yr & \multicolumn{1}{c}{ Reference } \\
\hline \multirow{2}{*}{$\mathrm{SO}_{2}$} & GEIA industrial emissions 1B.1 & 66.6 & Benkovitz et al. $[1996]$ \\
& biomass burning & 2.3 & Spiro et al. $[1992]$ \\
& aircraft & 0.1 & Baughcum et al. $[1993]$ \\
\multirow{2}{*}{ DMS } & volcanoes (noneruptive) & 3.5 & Spiro et al. [1992] \\
& oceanic source & 10.7 & Kettle et al. [1999]; Liss and Merlivat [1986]
\end{tabular}

To get DMS surface air concentrations, we assume the flux from ocean to air is proportional to the sea water concentration of DMS times the sea-to-air transfer coefficient give by Liss and Merlivat [1986]. The transfer coefficient is proportional to the model surface $(10 \mathrm{~m})$ winds, which are generated as a balance between momentum transfer in the boundary layer and frictional drag at the surface. These surface winds are somewhat slower than observed. A DMS source generated by observed winds, derived from (1993-1994) special sensor microwave imagers (SSM/I) [Atlas et al., 1996], would increase the DMS source by $42 \%$. Terrestrial biospheric sulfur sources are neglected.

\subsection{Chemistry}

DMS is oxidized by $\mathrm{OH}$, generating $\mathrm{SO}_{2}$ and MSA:

$$
\mathrm{DMS}+\mathrm{OH} \rightarrow \mathrm{SO}_{2}
$$

and

$$
\mathrm{DMS}+\mathrm{OH} \rightarrow 0.75 \mathrm{SO}_{2}+0.25 \mathrm{MSA},
$$

using the rates given by Chin et al. [1996]; we do not include the additional oxidant (amounting to a doubling of oxidation rates) of Chin et al. [1996]. We also include nighttime oxidation of DMS by $\mathrm{NO}_{3}$, using the rate constant from Atkınson et al. [1992]. Monthly average three-dimensional (3-D) $\mathrm{NO}_{3}$ fields are from Wang et al. $[1998 \mathrm{a}, \mathrm{b}, \mathrm{c}]$.

For (dry) oxidation of $\mathrm{SO}_{2}$ by $\mathrm{OH}$ to form sulfate, we use the rates given by Atkinson et al. [1992].

Formation of $\mathrm{H}_{2} \mathrm{O}_{2}$ occurs by

$$
\mathrm{HO}_{2}+\mathrm{HO}_{2} \rightarrow \mathrm{H}_{2} \mathrm{O}_{2}+\mathrm{O}_{2}
$$

and

$$
\mathrm{HO}_{2}+\mathrm{HO}_{2}+\mathrm{M} \rightarrow \mathrm{H}_{2} \mathrm{O}_{2}+\mathrm{O}_{2} .
$$

The rates for these reactions are enhanced, approximately doubled, in the presence of water vapor. The rates are taken from Atkinson et al. [1992].

Hydrogen peroxide is destroyed photochemically and by reaction with $\mathrm{OH}$, using the reaction rate from Atkinson et al. [1992]. Five day average 3-D fields for the photolysis rate of $\mathrm{H}_{2} \mathrm{O}_{2}$, as well as the $\mathrm{OH}$ and $\mathrm{HO}_{2}$ concentrations are from C. Spivakovsky (personal communication, 1996).

Sulfate formation within liquid water clouds is given by:

$$
\mathrm{HSO}_{3}^{-}+\mathrm{H}_{2} \mathrm{O}_{2}(\mathrm{aq})+\mathrm{H}^{+} \rightarrow \mathrm{SO}_{4}^{-2}+\mathrm{H}_{2} \mathrm{O}+2 \mathrm{H}^{+}
$$

so that

$$
\frac{d\left[\mathrm{SO}_{4}^{-2}\right]}{d t}=k\left[\mathrm{HSO}_{3}^{-1}\right]\left[\mathrm{H}^{+}\right]\left[\mathrm{H}_{2} \mathrm{O}_{2}(\mathrm{aq})\right]
$$

where $k$ is taken from Jacob [1986]. We use the dissociation of $\mathrm{SO}_{2}(\mathrm{aq})$,

$$
\mathrm{SO}_{2}(\mathrm{aq}) \rightarrow \mathrm{HSO}_{3}^{-}+\mathrm{H}^{+},
$$

with equilibrium constant $K_{1}$ taken from Jacob [1986]. Using Henry's law and equation (7), equation (6) becomes:

$$
\frac{d\left[\mathrm{SO}_{4}^{-2}\right]}{d t}=k K_{1} K_{\mathrm{H}}\left(\mathrm{SO}_{2}\right) K_{\mathrm{H}}\left(\mathrm{H}_{2} \mathrm{O}_{2}\right) P\left(\mathrm{SO}_{2}\right) P\left(\mathrm{H}_{2} \mathrm{O}_{2}\right),
$$

where $K_{\mathrm{H}}$ refers to Henry's law coefficients, taken from Jacob [1986], and $P$ is the partial pressure. Equation (8) is applied with a model time step of 1 hour. To calculate sulfate air concentration, we use volume of cloud water (within clouds) or volume of precipitating water (below clouds), taken from the GCM. Any remaining $\mathrm{SO}_{2}$ and $\mathrm{H}_{2} \mathrm{O}_{2}$ following formation of sulfate is subject to precipitation scavenging, described in the following section.

\subsection{Deposition}

The aerosols and the dissolved gases, $\mathrm{SO}_{2}$ and $\mathrm{H}_{2} \mathrm{O}_{2}$, remaining after sulfate formation are scavenged by precipitation. We assume the sulfate and MSA aerosols are fully soluble, and $\mathrm{SO}_{2}$ and $\mathrm{H}_{2} \mathrm{O}_{2}$ solubility are determined by an effective Henry's law assuming pH of 4.5. Scavenging in convective and large-scale or stratiform clouds are handled separately. Model moist convection and stratiform cloud schemes are described in Del Genio and Yao [1993] and Del Genio et al. [1996]. We include brief summaries of the GCM schemes below.

The moist convective updraft mass flux and grid box fraction is determined by the amount of instability relative to the wet adiabat. Each moist convective event includes one nonentraining and one entraining plume that grows fractionally at a rate of $0.2 \mathrm{~km}^{-1}$. The upward flux is balanced by the sum of subsidence in the grid box and plume downdrafts. The downdrafts are composed of half plume and half surrounding air, and their mass flux is assumed to be one third of the updraft 
mass flux. All water droplets fall during the model time step (which is 1 hour for cloud processes), except for the amount that is evaporated or detrained. All water condensed above a certain level (typically 550 mbar) is detrained into cirrus anvils and added to the large-scale cloud prognostic liquid water budget.

Transport of chemical species follows the convective air mass transport and scavenging is applied only to species within (or below) the cloud updraft. We treat the dissolved species as the condensed water in the GCM is treated. Thus, all dissolved species are assumed to be removed and deposited, except for the fraction that is detrained or evaporated. Detrained species are returned to the air (in this sense we do not follow the GCM; we do not have a dissolved species budget).

Stratiform clouds form and then grow after the relative humidity exceeds the threshold of $60 \%$. These are the dominant cloud type in the extratropics except during the summers, and they generate about one third of GCM precipitation. They include detrained anvils from convective clouds, so that stratiform precipitation makes up about $15 \%$ of the precipitation in the tropics. Cloud water content $m$ is carried as a prognostic variable in the GCM. Precipitation formation is parameterized as

$$
P=\beta m=C_{0} m\left\{1-\exp \left[-\left(\frac{\mu}{\mu_{r}}\right)^{4}\right]\right\}+C_{1} P_{r} m
$$

where $\mu$ is the cloud water density within the cloud, $\mu_{r}$ is a critical value for the onset of rapid precipitation (= $0.5 \mathrm{~g} / \mathrm{m}^{3}$ over the oceans, 1.0 over land, 0.1 for ice phase clouds), $P_{r}$ is the precipitation flux entering from the grid box layer above, and $C_{1}$ is an efficiency factor for accretion of cloud water by precipitation $\left(=1 \mathrm{~m}^{2} / \mathrm{kg}\right)$. $C_{0}$ is the limiting autoconversion rate for large $\mu$ and is parameterized in the GCM in terms of the large-scale vertical velocity $w$, so that $C_{0}=10^{-4} \mathrm{~s}^{-1} 10^{-w /(1 \mathrm{~cm} / \mathrm{s})}$ for positive $w$, and $C_{0}=10^{-4} \mathrm{~s}^{-1}$ for negative $w$. The rate of conversion of cloud water to rainwater is $\beta$ and has a maximum value of $\beta_{\max }=C_{0}+C_{1} P_{r}$. Following microphysical processes, the cloudy gridbox fraction $b$ is updated and is proportional to the difference between the average grid box relative humidity and the relative humidity in the clear fraction of the grid box.

For stratiform in-cloud scavenging we apply a firstorder rate loss parameterization. Following Giorgi and Chameides [1986] and based on data from ten Brink et al. [1987], the rate of conversion of cloud water to rainwater $\beta$ is the first-order rate coefficient. The chemical species loss $\Delta T$ in a model time step $\Delta t$ is then

$$
\Delta T=T_{0} F[\exp (-\beta \Delta t)-1],
$$

where $T_{0}$ is the initial concentration and $F$ is the fraction of precipitating grid box. The GCM calculates the fraction of grid box containing cloud, $b$; however, it does not determine how much of the cloud is precipitating. To account for this we use $F=b \beta \Delta t$, where $\beta \Delta t$ is the ratio of precipitating water to total condensed water.
Below precipitating clouds we scavenge aerosols and soluble gases. Sulfate formation is calculated for falling precipitation using equation (8) and volume of falling precipitation. The model time step used is again 1 hour. Leftover $\mathrm{H}_{2} \mathrm{O}_{2}(\mathrm{aq})$ and $\mathrm{SO}_{2}(\mathrm{aq})$ dissolved in the raindrops, as determined by the modified Henry's law, are scavenged. Aerosol impaction by raindrops is assumed to be first-order with respect to the precipitation amount [Dana and Hales, 1976] and has the form

$$
\Delta T=T_{0} F\left[\exp \left(-P^{\prime}(L+1) \times 0.1\right)-1\right],
$$

where $P^{\prime}(L+1)$ is the precipitation amount from the grid box layer above in units of millimeters, $L$ is the model layer, $F$ refers to the lowest precipitating cloud layer, and $0.1 \mathrm{~mm}^{-1}$ is the washout rate constant [Dana and Hales, 1976].

We allow scavenged species to return to the air if falling precipitation evaporates (below cloud or in convective downdrafts). Dissolved gas is returned in proportion to water evaporation. For aerosols we multiply this proportion by $1 / 2$, unless total evaporation occurs. The factor of $1 / 2$ is chosen arbitrarily to account for the varying sizes of the droplets: some drops will evaporate completely and liberate an aerosol particle, while others will not.

Dry deposition of $\mathrm{SO}_{2}, \mathrm{H}_{2} \mathrm{O}_{2}$, sulfate, and MSA is done using the resistance-in-series scheme of Wesely and Hicks [1977]. We use the method described in Chin et al. [1996], except we calculate the aerodynamic resistances using the GCM surface momentum and heat fluxes. Our calculated deposition velocities for $\mathrm{SO}_{2}$ and sulfate are very similar to those presented by Chin et al. [1996], except that sulfate deposition velocity over the oceans is higher, typically about $0.1 \mathrm{~cm} / \mathrm{s}$.

\section{Model Results}

We performed three 6-year model simulations: one full run (with prognostic $\mathrm{H}_{2} \mathrm{O}_{2}$ ), one full run with fixed $\mathrm{H}_{2} \mathrm{O}_{2}$ fields, and one with the natural source only. We show results based on the last 5 years of the simulations, unless stated otherwise. Table 2 shows the model sulfur budget along with those of other published global models. Roelofs et al. [1998] and Lelieveld et al. [1997] are similar, so we include the former only. Lelieveld et al. [1997] has a lower $\mathrm{SO}_{2}$ burden $(0.56 \mathrm{Tg} \mathrm{S})$ than Roelofs et al. [1998], perhaps because they used an immediate additional $15 \%$ dry deposition of emitted $\mathrm{SO}_{2}$. Unless noted, our comparison with Roelofs et al. [1998] also applies to Lelieveld et al. [1997].

The large variation in $\mathrm{SO}_{2}$ wet deposition amongst model budgets results from the degree to which $\mathrm{SO}_{2}$ oxidized within clouds is accounted as $\mathrm{SO}_{2}$ deposition or sulfate deposition. In our case, as well as that of Roelofs et al. [1998], the latter is assumed.

Our DMS source is low compared with the other models because the source from Kettle et al. [1999] is lower than that of Bates et al. [1987, 1992] which was used 
Table 2. Sulfur Budgets

\begin{tabular}{|c|c|c|c|c|c|c|c|}
\hline & $\begin{array}{l}\text { This } \\
\text { Study }\end{array}$ & $\begin{array}{c}\text { Langner } \\
\text { and Rodhe } \\
{[1991]}\end{array}$ & $\begin{array}{l}\text { Pham } \\
\text { et al. } \\
{[1995]}\end{array}$ & $\begin{array}{c}\text { Chin } \\
\text { et al. } \\
{[1996]}\end{array}$ & $\begin{array}{c}\text { Feichter } \\
\text { et al. } \\
{[1996]}\end{array}$ & $\begin{array}{l}\text { Chuang } \\
\text { et al. } \\
\text { [1997] }\end{array}$ & $\begin{array}{c}\text { Roclofs } \\
\text { et al. } \\
{[1998]}\end{array}$ \\
\hline \multicolumn{8}{|c|}{$\mathrm{SO}_{2}$} \\
\hline Sources, $\mathrm{Tg} S / y r$ & 80.4 & 94.5 & 122.8 & 95.6 & 100.5 & 106.0 & 90.0 \\
\hline Industrial emission & 64.6 & 66.5 & 92.0 & 65.1 & 77.6 & 75.7 & 63.7 \\
\hline Biomass burning & 2.3 & 2.5 & 9.2 & 2.3 & 2.5 & 2.2 & 2.3 \\
\hline Volcanoes & 3.5 & 8.5 & 2.9 & 6.7 & 3.5 & 3.4 & 7.8 \\
\hline Photochemistry & 10.0 & 17.0 & 18.7 & 21.5 & 16.9 & 24.7 & 16.2 \\
\hline Sinks, Tg S/yr & 80.4 & 94.5 & 122.8 & 95.6 & 100.5 & 106.0 & 90.0 \\
\hline Gas oxidation & 13.1 & 7.8 & 6.5 & 7.5 & 16.8 & 6.1 & 16.2 \\
\hline In-cloud oxid. & 31.6 & 42.0 & 55.5 & 41.6 & 34.5 & 42.3 & 57.8 \\
\hline Dry deposition & 35.5 & 30.5 & 55.0 & 26.6 & 40.2 & 38.7 & 16.0 \\
\hline Wet deposition & 0.2 & 14.2 & 5.8 & 19.9 & 9.0 & 18.9 & 0.0 \\
\hline Burden, Tg S & 0.56 & 0.30 & 0.20 & 0.34 & 0.43 & 0.36 & 0.61 \\
\hline Lifetime, days & 2.6 & 1.2 & 0.6 & 1.3 & 1.5 & 1.3 & 2.4 \\
\hline \multicolumn{8}{|c|}{ Sulfate } \\
\hline Sources, $\mathrm{Tg} \mathrm{S} / \mathrm{yr}$ & 46.6 & 53.3 & 62.0 & 49.1 & 51.3 & 48.4 & 78.0 \\
\hline Industrial emissions & 1.9 & 3.5 & 0.0 & 0.0 & 0.0 & 0.0 & 3.3 \\
\hline $\mathrm{SO}_{2}$ oxidation & 44.7 & 49.8 & 62.0 & 49.1 & 51.3 & 48.4 & 74.7 \\
\hline Sinks, $\mathrm{Tg} \mathrm{S} / \mathrm{yr}$ & 46.6 & 53.1 & 62.0 & 49.1 & 51.3 & 48.4 & 78.0 \\
\hline Dry deposition & 9.2 & 8.6 & 17.0 & 5.6 & 6.7 & 5.2 & 17.0 \\
\hline Wet deposition & 37.4 & 44.5 & 45.0 & 43.5 & 44.6 & 43.2 & 61.0 \\
\hline Burden, Tg S & 0.73 & 0.77 & 0.80 & 0.53 & 0.61 & 0.55 & 0.96 \\
\hline Lifetime, days & 5.7 & 4.6 & 4.7 & 3.9 & 4.3 & 4.1 & 4.7 \\
\hline \multicolumn{8}{|c|}{$D M S$} \\
\hline Source, Tg S/yr & 10.7 & 16.0 & 20.0 & 21.8 & 16.9 & 23.7 & 16.6 \\
\hline Sink (oxidation), $\mathrm{Tg} \mathrm{S} / \mathrm{yr}$ & 10.7 & 16.0 & 20.0 & 21.8 & 16.9 & 23.7 & 16.6 \\
\hline Burden, Gg S & 56.0 & 130.0 & 50.0 & 60.0 & 100.0 & & \\
\hline Lifetime, days & 1.9 & 3.0 & 0.9 & 1.0 & 2.2 & & \\
\hline \multicolumn{8}{|c|}{$M S A$} \\
\hline Source (DMS), Tg S/yr & 1.1 & & 1.2 & 1.1 & & & \\
\hline Sinks, $\mathrm{Tg} \mathrm{S} / \mathrm{yr}$ & 1.1 & & 1.2 & 1.1 & & & \\
\hline Dry deposition & 0.2 & & 0.5 & 0.1 & & & \\
\hline Wet deposition & 0.9 & & 0.7 & 1.0 & & & \\
\hline Burden, Gg S & 23.0 & & 20.0 & 20.0 & & & \\
\hline Lifetime, days & 7.6 & & 6.1 & 6.2 & & & \\
\hline
\end{tabular}

in previous models. The greatest difference is in the southern oceans (south of $45^{\circ} \mathrm{S}$ ), where the zonal annual average Kettle et al. source is about half the Bates et al. [1987] source. This seems to have greatly remedied the excessively high DMS concentrations in the oceans around Antarctica during austral summer, a difficulty in many previous studies [e.g., Langner and Rodhe, 1991; Glantz et al., 1997]. The (zonal annual average) Kettle et al. source is lower than the Bates et al. source for latitudes southward of about $30^{\circ} \mathrm{N}$ but is higher at northernmost latitudes. As was noted above, our DMS source is also low because the GCM surface winds are somewhat slow; however, most of the previous studies likely suffer from similarly deficient model wind speeds.

The $\mathrm{SO}_{2}$ burden and lifetime are larger than in most previous models, except for that of Roelofs et al. [1998].
Figure 1 shows the zonal, annual average concentrations. Our $\mathrm{SO}_{2}$ concentrations in the free troposphere of the Northern Hemisphere are roughly double those shown by Feichter et al. [1996] (the only other modelers to publish a zonal average concentration figure). Our high $\mathrm{SO}_{2}$ burden may be attributed largely to depletion of prognostic $\mathrm{H}_{2} \mathrm{O}_{2}$, particularly during winter, which can take a day or more to replenish. In models with fixed $\mathrm{H}_{2} \mathrm{O}_{2}$, the oxidant is reset to the monthly average value at each time step, so that replenishment is instantaneous. In our model and in that of Roelofs et al. [1998], $\mathrm{SO}_{2}$ in-cloud oxidation is therefore less efficient. To investigate this, we performed a simulation using monthly average three-dimensional $\mathrm{H}_{2} \mathrm{O}_{2}$ fields saved from the prognostic $\mathrm{H}_{2} \mathrm{O}_{2}$ calculation. In this run, we get $16 \%$ more in-cloud oxidation, an $\mathrm{SO}_{2}$ burden of 


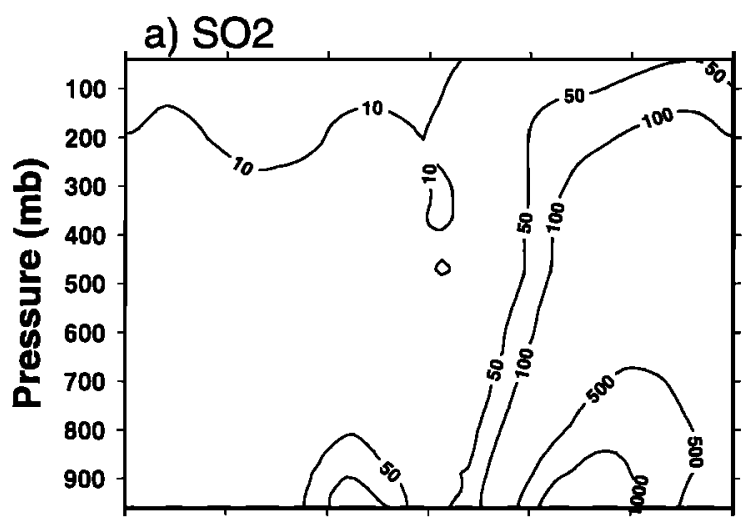

c) DMS

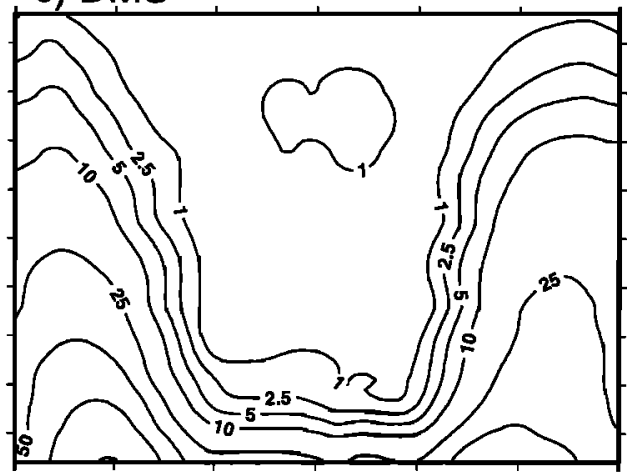

b) sulfate

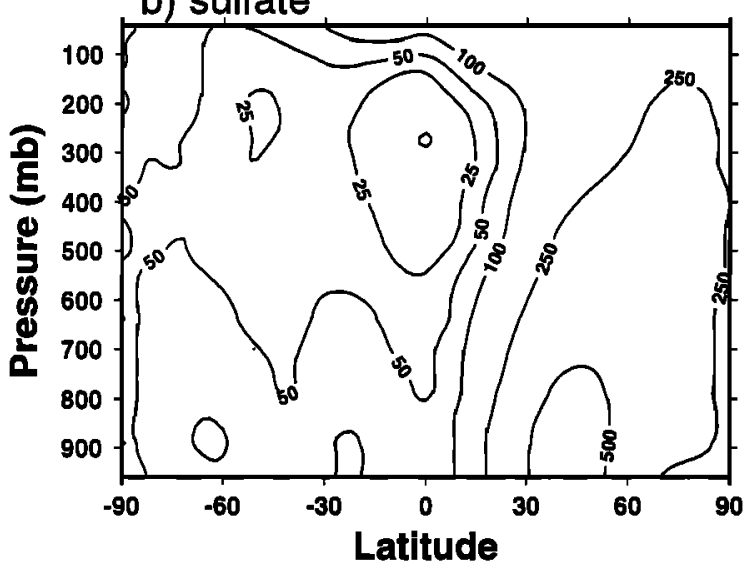

d) $\mathrm{H}_{2} \mathrm{O} 2$

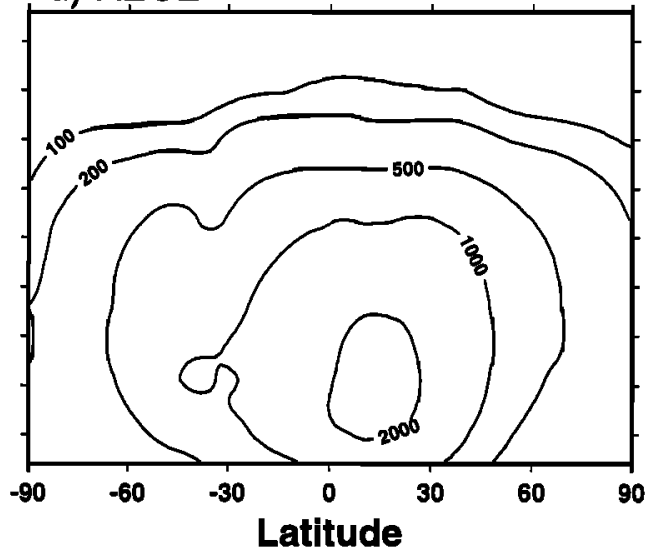

Figure 1. Annual, zonal average concentrations (pptv) for (a) $\mathrm{SO}_{2}$, (b) sulfate, (c) DMS, and (d) $\mathrm{H}_{2} \mathrm{O}_{2}$.

$0.45 \mathrm{Tg} \mathrm{S}$, and a lifetime of 2.0 days. The global annual average sulfate burden is not affected, since the increased sulfate production is accompanied by increased wet scavenging of sulfate (the sulfate lifetime decreases to 5.3 days). Figure 2 shows zonal average ratios between results from the run with prognostic $\mathrm{H}_{2} \mathrm{O}_{2}$ and the run using fixed $\mathrm{H}_{2} \mathrm{O}_{2}$ fields. Typically, the prognostic $\mathrm{H}_{2} \mathrm{O}_{2}$ runs have about $20-30 \%$ more $\mathrm{SO}_{2}$ in the polluted Northern Hemisphere than the fixed $\mathrm{H}_{2} \mathrm{O}_{2}$ case. The prognostic $\mathrm{H}_{2} \mathrm{O}_{2}$ generates lower sulfate concentrations at the surface and higher concentrations aloft. Roelofs et al. [1998] also performed comparisons between prognostic and fixed $\mathrm{H}_{2} \mathrm{O}_{2}$ simulations. Their offline $\mathrm{H}_{2} \mathrm{O}_{2}$ produced $22 \%$ less $\mathrm{SO}_{2}$ northward of $30^{\circ} \mathrm{N}$. A larger effect was seen if they used $\mathrm{H}_{2} \mathrm{O}_{2}$ generated by a model with no $\mathrm{SO}_{2}$ oxidation sink: in this case they had $30 \%$ less $\mathrm{SO}_{2}$ in the same region.

A second, related, reason for high $\mathrm{SO}_{2}$ in the free troposphere is because $\mathrm{SO}_{2}$ in polluted regions is often not completely oxidized in moist convective plumes. Plate 1 shows the net, annual average, change of $\mathrm{SO}_{2}$ by convection, including the effects of chemistry, transport, and scavenging. Over the polluted regions of the Northern Hemisphere, moist convection delivers more $\mathrm{SO}_{2}$ to the free troposphere than it oxidizes. This is related to the depletion of $\mathrm{H}_{2} \mathrm{O}_{2}$, and the amount of $\mathrm{SO}_{2}$ delivered to the free troposphere is 3 times greater during wintertime than summertime.

Comparison of zonal annual average sulfate with previous models [Feichter et al., 1996; Chin et al., 1996; and Langner and Rodhe, 1991] indicates that our sulfate concentrations in the polluted Northern Hemisphere are also higher, typically double. One exception is Pham et al. [1995], who had free troposphere sulfate concentrations nearly as high as ours, but they also had a high $\mathrm{SO}_{2}$ source. Roelofs et al. [1998] also reported very high sulfate concentrations in the free troposphere, up to 300 parts per trillion (ppt). Like Roelofs et al. [1998], we might attribute our high sulfate concentrations to low scavenging efficiencies compared with the other models. However, it is likely that the high sulfate results from oxidation of the large $\mathrm{SO}_{2}$ reservoir in the free troposphere. We note that the aircraft source in this model, which is only about $0.1 \%$ of the total source, contributes less than $3 \%$ to the sulfate burden in the upper troposphere of the northern hemisphere.

The $\mathrm{H}_{2} \mathrm{O}_{2}$ concentrations produced in this model are similar to previous models [e.g. Horowitz et al., 1998; Wang et al., 1998b; Dentener and Crutzen, 1993]. Table 3 has the budgets for $\mathrm{H}_{2} \mathrm{O}_{2}$. The primary sink is from dry chemistry. Wet deposition and oxidation of $\mathrm{SO}_{2}$ constitute only $11 \%$ and $4 \%$ of the total sink, re- 

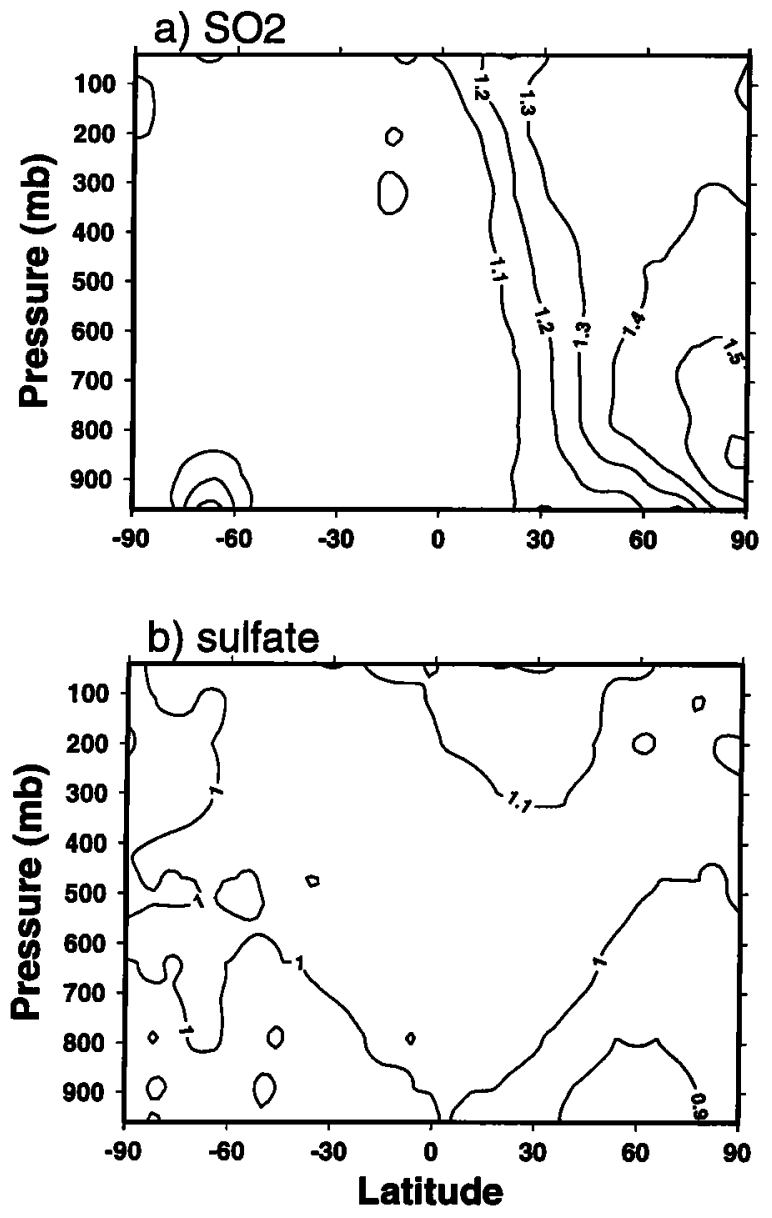

Figure 2. Ratio between zonal, annual average results from the run with prognostic $\mathrm{H}_{2} \mathrm{O}_{2}$ and a run with fixed $\mathrm{H}_{2} \mathrm{O}_{2}$ for (a) $\mathrm{SO}_{2}$ and (b) sulfate. spectively. Globally, it thus seems likely that the loss due to $\mathrm{SO}_{2}$ oxidation is of minor importance in tropospheric chemistry models, although its importance regionally has been demonstrated by Roeloffs et al. [1998]. The $\mathrm{H}_{2} \mathrm{O}_{2}$ lifetime varies seasonally, so that in the Northern Hemisphere, it's lifetime is 1.2 days in July and 1.7 days in January. Thus the difficulty of regenerating $\mathrm{H}_{2} \mathrm{O}_{2}$ following oxidation and precipitation is greater during the winter. The zonal average $\mathrm{H}_{2} \mathrm{O}_{2}$, shown in Figure 1, is similar to the fixed $\mathrm{H}_{2} \mathrm{O}_{2}$ fields used by Chin et al. [1996] and Feichter et al. [1996], although our concentrations are somewhat higher than those in the latter study.

Figures 3,4 and 5 show DMS, $\mathrm{SO}_{2}$ and sulfate concentrations during January and July, at the surface and at about $6 \mathrm{~km}$. Both $\mathrm{SO}_{2}$ and sulfate have strong seasonalities over the Northern Hemisphere polluted regions, due to the greater availability of oxidants during the summertime. Thus $\mathrm{SO}_{2}$ peaks during the winter and sulfate during the summer. We note that the gradient of sulfate concentrations from low values in the tropical midtroposphere to high values at higher latitudes is much stronger than it was in the previous version of the GISS model [Chin et al., 1996], which had sulfate concentrations at least double the current model in the tropics. The earlier model lacked entraining convection, and therefore did not efficiently scavenge aerosols from the free troposphere [Koch et al., 1996].

In Figure 6 we show the global distribution of $\mathrm{OH}$ and $\mathrm{H}_{2} \mathrm{O}_{2}$ oxidation of $\mathrm{SO}_{2}$ in the atmospheric column. $\mathrm{OH}$ oxidation dominates in dry regions. Globally, $67 \%$ of the sulfate is produced by in-cloud oxidation, compared with over $80 \%$ in most previous models (exceptions are

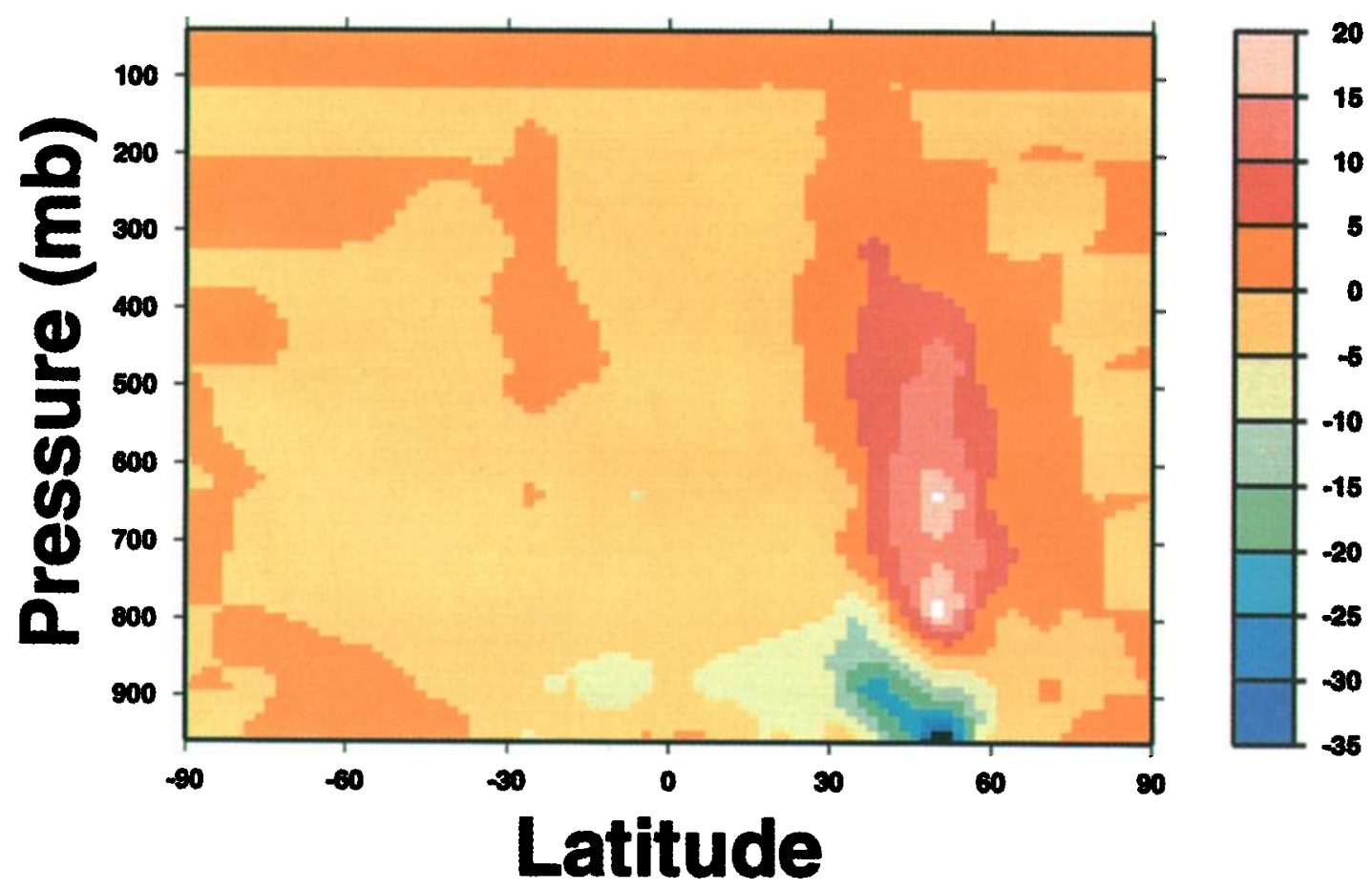

Plate 1. Annual, zonal total change of $\mathrm{SO}_{2}(\mathrm{~kg} / \mathrm{s})$ by moist convection, including changes due to transport, chemistry and scavenging. 
Table 3. $\mathrm{H}_{2} \mathrm{O}_{2}$ Budget

\begin{tabular}{lr}
\hline & $\mathrm{H}_{2} \mathrm{O}_{2}$ \\
\hline Source $\left(\mathrm{HO}_{2}\right), \mathrm{Tg} / \mathrm{yr}$ & 1125.0 \\
Sinks, $\mathrm{Tg} / \mathrm{yr}$ & 1125.0 \\
Dry chemistry & 825.0 \\
Dry deposition & 141.0 \\
Wet deposition & 125.0 \\
Wet chemistry & 34.0 \\
Burden, $\mathrm{Tg} \mathrm{H} \mathrm{O}_{2}$ & 4.2 \\
Lifetime, days & 1.4 \\
\end{tabular}

Feichter et al. [1997] with $67 \%$ and Roelofs et al. [1998] with $78 \%$ in-cloud production). Our high dry oxidation percent is related to the larger free-tropospheric $\mathrm{SO}_{2}$ levels.

We are interested in investigating the contribution of the natural source to the total sulfate burden for this model. Table 4 shows the $\mathrm{SO}_{2}$ and sulfate budgets for a natural source run. The sources for this case include DMS, volcanic emissions and $1 / 10$ of the biomass-burning source. Note that the $\mathrm{SO}_{2}$ lifetime, 1.8 days, is half the value for the full run. The natural $\mathrm{SO}_{2}$ source is about $17 \%$ of the total source and $23 \%$ of the sulfate burden is natural (Figure 7). There is some seasonal variability to this contribution: $43 \%$ of the burden is natural during January and $17 \%$ during July. The natural source contributes a lower amount to our total burden than has been found in previous studies. Chin and Jacob [1996] and Feichter et al. [1997] had a natural source which was about $30 \%$ of the total, but which contributed $60 \%$ and $44 \%$, respectively, to the sulfate burden. They argued that the natural source (volcanic eruptions and DMS) readily escapes the boundary layer while the anthropogenic source is more efficiently deposited or scavenged. In our model, a relatively large amount of anthropogenic $\mathrm{SO}_{2}$ escapes to the free troposphere, so that a greater amount of the total sulfate burden is anthropogenic. Our natural source strength is also lower; if we were to use observed (SSM/I) winds instead of the model winds, we estimate the anthropogenic contribution would still be at least $70 \%$. An additional factor affecting the burden is the scavenging efficiency. Chin et al. [1996] assumed $100 \%$ scavenging efficiency in moist convection, which reduced the anthropogenic contribution to the burden. In our model and in that of Feichter et al. [1996, 1997], convective detrainment returns dissolved species to the free troposphere, thus allowing greater anthropogenic contribution to the burden. The natural component of the sulfate burden is generally lower than $20 \%$ in the model's northern hemisphere, as is shown in Figure 7.

\section{Comparison With Observations}

We first compare model results with annual average surface observations, then consider seasonal variability, and finally compare with high altitude observations. Table 5 shows a comparison of annual average model concentrations with observations, averaged within regions. Table 6 has a comparison of modeled and observed sulfur wet deposition flux. The model S wet deposition flux is shown in Figure 8. All European data are from the Cooperative Program for Monitoring and Evaluation of the Long Range Transmission of Air Pollutants in Europe (EMEP) [e.g., Schaug et al., 1987]. We use years 1980-1990 from this data set. Over North America, we use data from the Eulerian Model Evaluation Field Study (EMEFS) [e.g., McNaughton and Vet, 1996] for surface concentration data. This data set is from 1988 to 1990 . For deposition flux over North America we use observations from the National Acid Deposition Project (NADP) between the years 1980 and 1990. All remaining sites are referenced by Chin et al. [1996].

As shown in Figure 9, there appear to be latitudedependent model biases in MSA. At high latitudes, model MSA is too high, at midlatitudes agreement is reasonably good, but at low latitudes the model is too low. As indicated in Tables 5 and 6, there are similar trends for $\mathrm{SO}_{2}$, sulfate, and sulfur deposition in remote locations. It is not clear, given the sparsity of DMS

\section{a) Jan: surface}

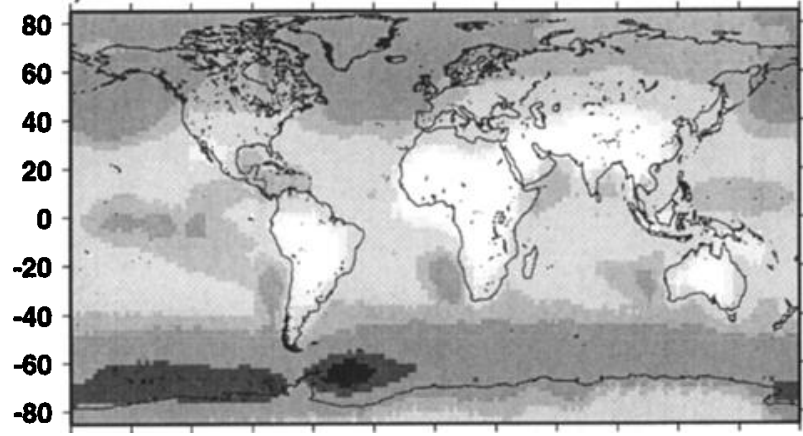

b) Jul: surface

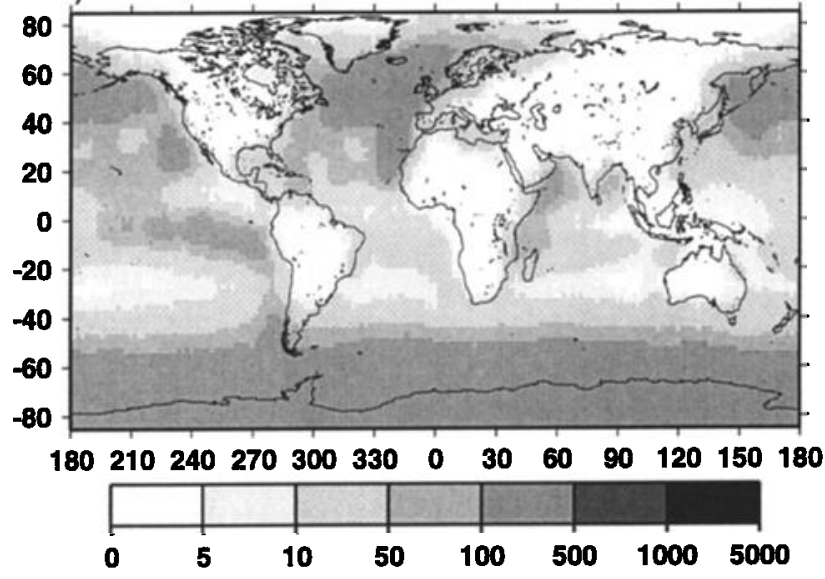

Figure 3. DMS surface concentrations (pptv) in (a) January and (b) July. 


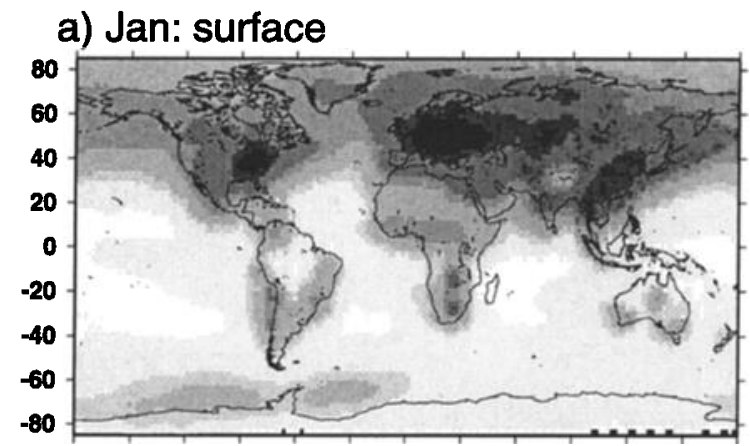

c) Jan: $6 \mathrm{~km}$

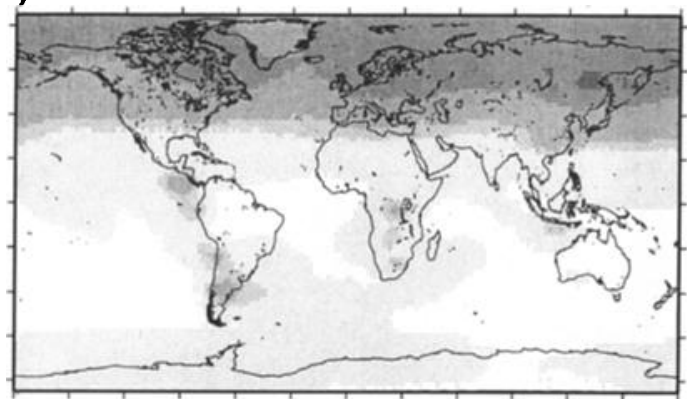

b) Jul: surface

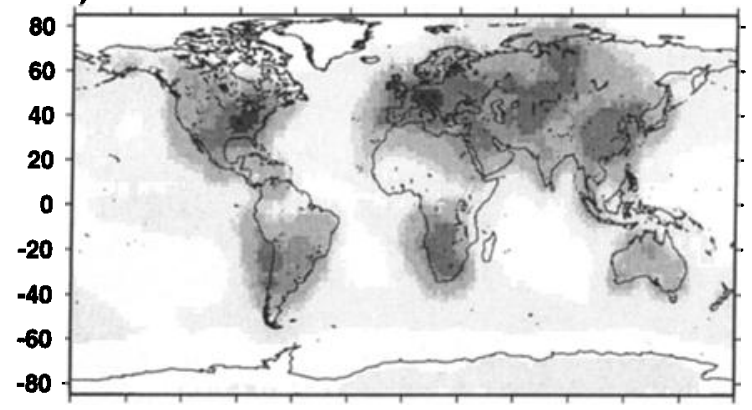

d) Jul: $6 \mathrm{~km}$
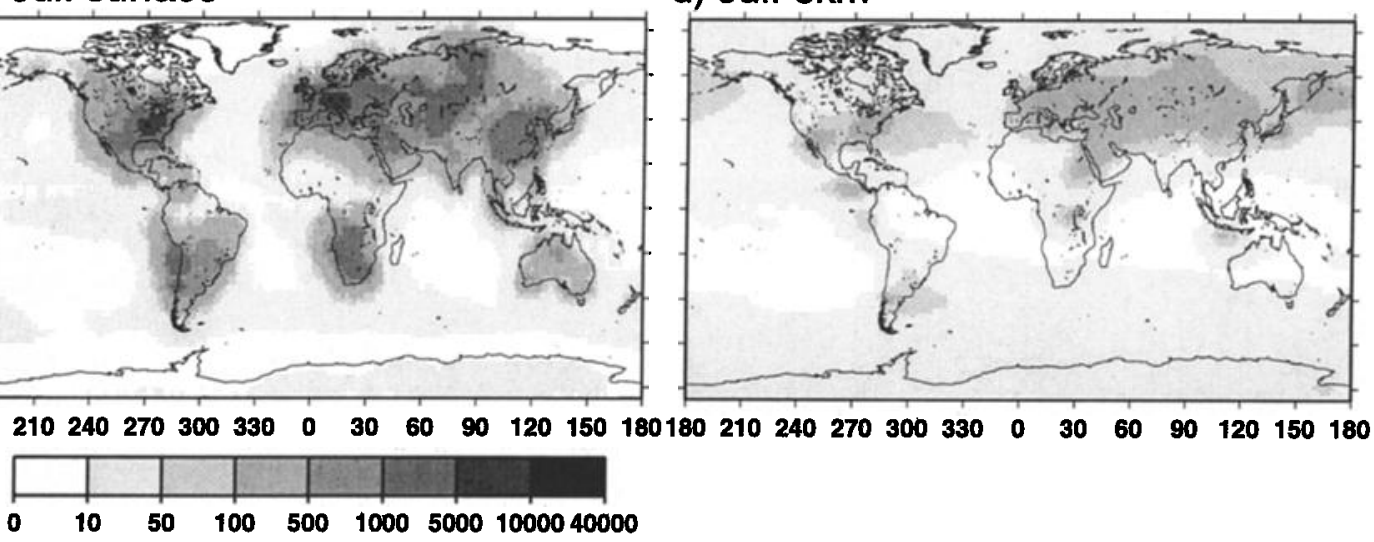

Figure 4. $\mathrm{SO}_{2}$ concentrations (pptv) at the surface in (a) January and (b) July and in layer 5 (approximately $6 \mathrm{~km}$ ) in (c) January and (d) July.

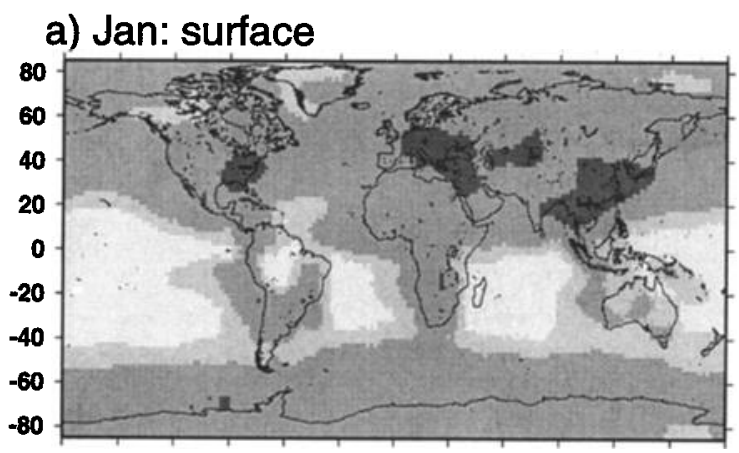

c) Jan: $6 \mathrm{~km}$

b) Jul: surface
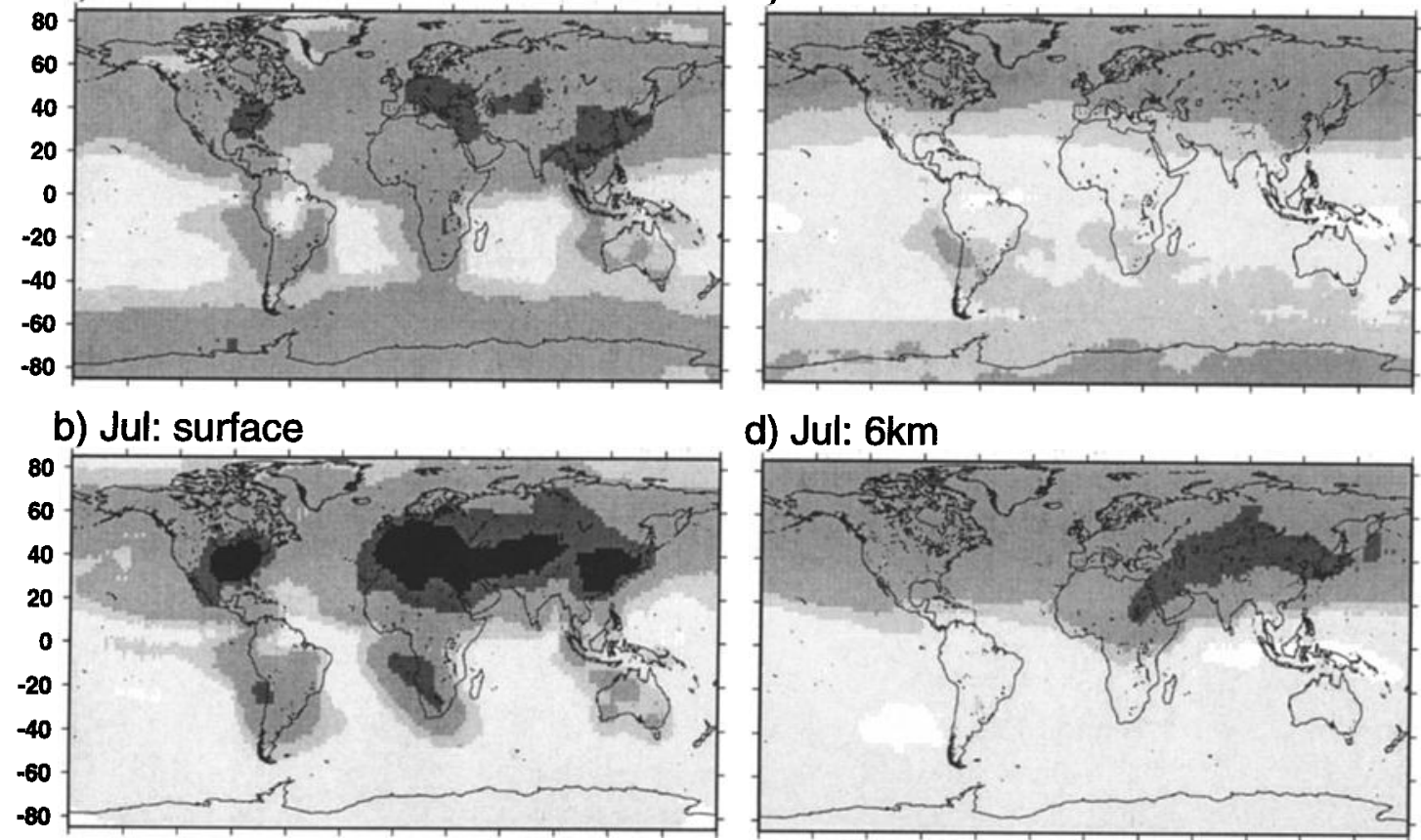

d) Jul: $6 \mathrm{~km}$

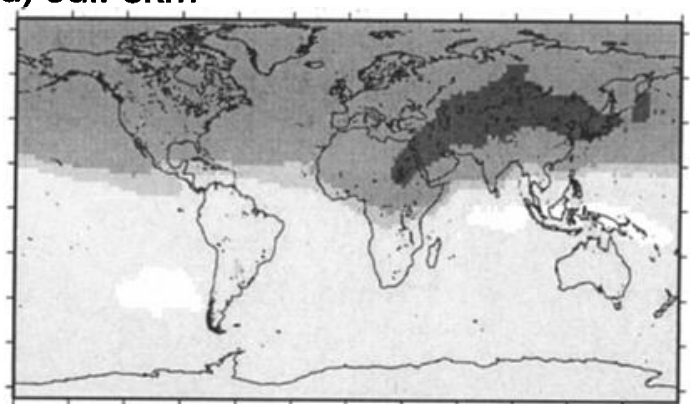

$\begin{array}{lllllllllllllllllllllllll}180 & 210 & 240 & 270 & 300 & 330 & 0 & 30 & 60 & 90 & 120 & 150 & 180180 & 210 & 240 & 270 & 300 & 330 & 0 & 30 & 60 & 90 & 120 & 150 & 180\end{array}$

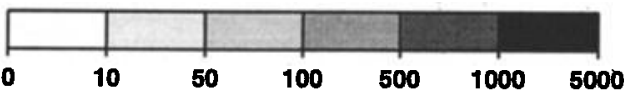

Figure 5. Sulfate concentrations (pptv), as in Figure 4. 


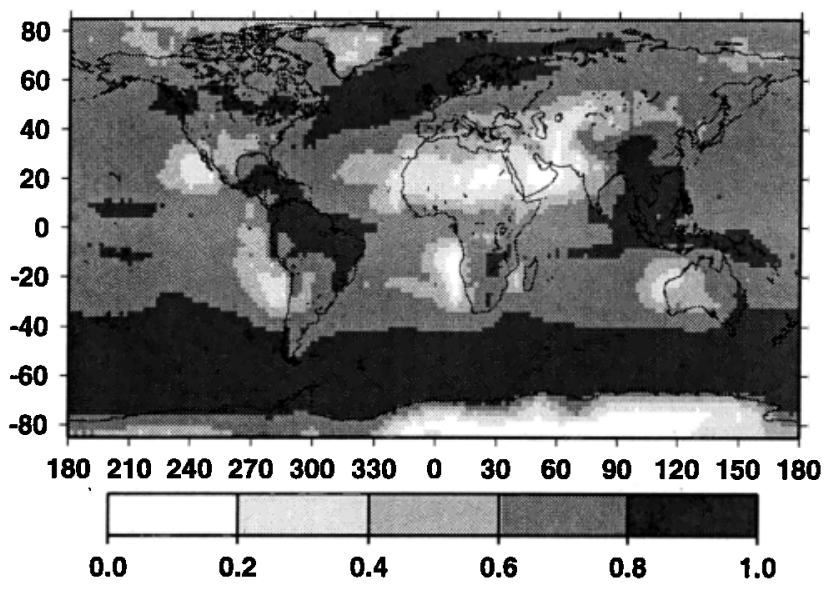

Figure 6. Annual average fraction of column sulfate produced by by $\mathrm{H}_{2} \mathrm{O}_{2}$ oxidation, with the remaining generated by $\mathrm{OH}$ oxidation.

observations, whether the difficulty is with the DMS source itself or with errors in oxidation rates or products. Using a larger sea-air transfer function, such as that of Wanninkhof [1992], would approximately double the model MSA values at high latitudes but would increase low-latitude values by a lesser amount, $\sim 50 \%$.

Another bias is the large model excess of $\mathrm{SO}_{2}$ over polluted regions, which is typical of previous studies [e.g., Pham et al., 1995; Feichter et al., 1996; Roelofs et al., 1998]. Insufficient oxidation and/or insufficient transport out of the boundary layer have been suggested as possible reasons for this difficulty. Sulfate surface concentrations and $\mathrm{S}$ deposition over North America agree quite well with observations. Over Europe, however, sulfate is low by about $20-30 \%$ and $\mathrm{S}$ deposition is low by a factor of 3-4. Thus over Europe it appears that the model has too little $\mathrm{SO}_{2}$ oxidation and deposition.

A brief comparison of model $\mathrm{H}_{2} \mathrm{O}_{2}$ with observations shows reasonable agreement. Horowitz et al. [1998] provide $3 \mathrm{H}_{2} \mathrm{O}_{2}$ summertime surface concentrations over North America, which have an average value of 1200 pptv. Our model average at these sites is 1800 pptv in summertime.

As was discussed above, the use of prognostic $\mathrm{H}_{2} \mathrm{O}_{2}$ has the effect of increasing surface $\mathrm{SO}_{2}$ and decreasing surface sulfate. The fixed $\mathrm{H}_{2} \mathrm{O}_{2}$ simulation has typically about $5 \%$ more sulfate at the surface, $5-10 \%$ less surface $\mathrm{SO}_{2}$, and about $10 \%$ greater deposition flux. It thus performs somewhat better in Europe than the prognostic $\mathrm{H}_{2} \mathrm{O}_{2}$. Over North America the prognostic $\mathrm{H}_{2} \mathrm{O}_{2}$ gives better sulfate and $\mathrm{S}$ deposition in the east, but the fixed $\mathrm{H}_{2} \mathrm{O}_{2}$ results in lower (better) $\mathrm{SO}_{2}$ concentration and $\mathrm{S}$ deposition in the west.

Figures 10 and 11 are a representative sample of sites showing seasonality behaviors of $\mathrm{SO}_{2}$ and sulfate over Europe and North America. In Figure 10 we see that the model bias is greater during the wintertime at the northernmost sites (e.g., Figures 10a, 10e, and 10f). The bias occurs throughout the year farther south (e.g., Figures $10 \mathrm{~b}$ and $10 \mathrm{~h}$ ). Although at most locations the bias is quite high, in some locations, e.g., Arendsville, Pennsylvania (Figure 10g), agreement is good. Figure $10 \mathrm{c}$ shows two sets of observations within one GCM gridbox in Germany that have $\mathrm{SO}_{2}$ concentrations differing by as much as a factor of 2 ; this demonstrates the degree of variability among observed values. Finally, as shown in Figure 10d, there are a few locations where the model $\mathrm{SO}_{2}$ is lower than observed.

Figure 11 shows sulfate at the same sites as in Figure 10. Typically, the sulfate in Europe is observed to peak during the springtime or lacks clear seasonality. The model tends to peak during summertime. The model sulfate is generally low during the wintertime in Europe, so that increased wintertime oxidation in Europe would improve the simulation. Many of the northernmost sites in North America have flat seasonality like in much of Europe (e.g., Figure 11e). Further south in North America, the sulfate is observed to be highest during summertime. The model successfully simulates this, although it tends to be less sharply peaked than observed (Figures $10 \mathrm{~g}$ and $10 \mathrm{~h}$ ). Note that the two sites in Germany with very different $\mathrm{SO}_{2}$ concentrations differ much less in their sulfate concentrations.

We have seen that the model has excessive $\mathrm{SO}_{2}$ over North America and Europe, with larger biases occuring in the northernmost regions during wintertime. The greater $\mathrm{SO}_{2}$ wintertime bias may be due to insufficient dry deposition of $\mathrm{SO}_{2}$ to frozen surfaces. The bias might also be an apparent one, due to the fact that most $\mathrm{SO}_{2}$ is released from smokestacks above wintertime inversion layers, while the measurements are made close to the surface. Although $\mathrm{SO}_{2}$ biases are similar in Europe and North America, the sulfate and deposition flux are fairly well simulated over North America but poorly simulated over Europe. In Europe the model sulfate is underestimated, particularly during winter, and the deposition flux is much lower than observed. Additional oxidation during winter would thus improve the simulation in Europe but probably would worsen the sim-

Table 4. Natural Source Budget

\begin{tabular}{lr}
\hline & Natural \\
\hline $\mathrm{SO}_{2}$ source, Tg S/yr & 13.8 \\
$\mathrm{SO}_{2}$ sinks, $\mathrm{Tg} \mathrm{S} / \mathrm{yr}$ & \\
Gas oxidation & 2.2 \\
In-cloud oxidation & 8.2 \\
Dry deposition & 2.8 \\
Wet deposition & 0.6 \\
$\mathrm{SO}_{2}$ burden, Gg S & 70.0 \\
$\mathrm{SO}_{2}$ lifetime, days & 1.8 \\
$\mathrm{Sulfate}$ burden, Gg S & 170.0 \\
Sulfate lifetime, days & 5.8 \\
\hline
\end{tabular}



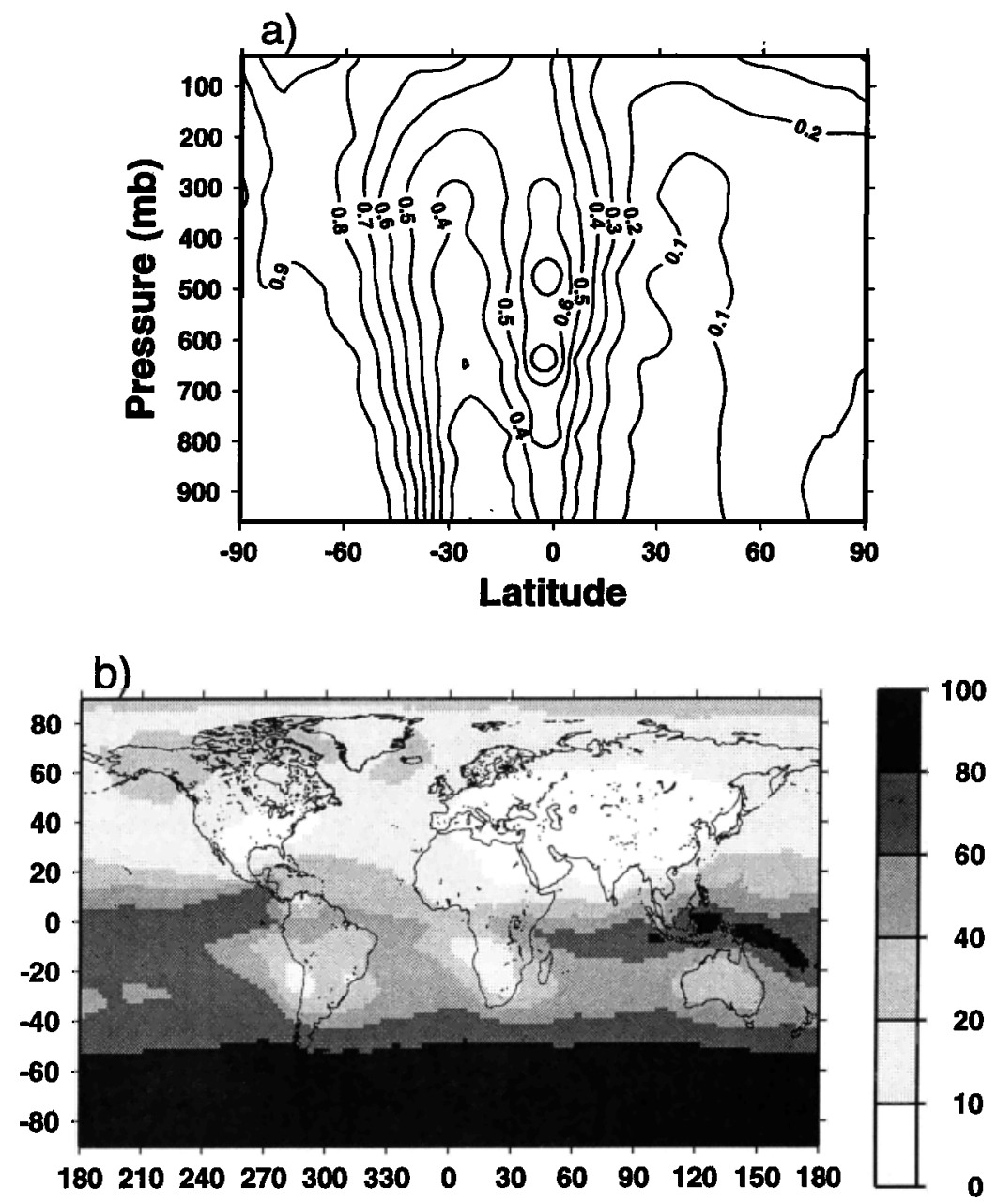

Figure 7. (a) Zonal, annual average fraction of sulfate derived from a natural source Percentage of annual average column sulfate having a natural source.

ulation in North America. The difficulty in simulating seasonality on both continents is common to models, as was discussed in Kasibhatla et al. [1997].

Observations presented so far have been from surface measurements. In order to determine whether we have excessive $\mathrm{SO}_{2}$ or sulfate in the free troposphere it is important to compare with high altitude observations. In Figure $11 \mathrm{i}$ we show comparison of the model with data from 1989-1996 at Mauna Loa $(3400 \mathrm{~m})$, which were filtered to remove the effects of volcanic sulfur emissions and boundary layer up-slope contamination (B. Huebert, personal communication, 1998). The model is somewhat low in the spring and high in the summer, but overall agreement suggests reasonable sulfate levels in this remote region. We also have data from two high-altitude continental sites, Jungfraujoch, Switzerland $(3573 \mathrm{~m})$, and Yampa, Colorado $(2354 \mathrm{~m})$. The model $\mathrm{SO}_{2}$ is about $66 \%$ too high at Yampa and $41 \%$ too high at Jungfraujoch. Model sulfate is about $41 \%$ too high at Yampa and 58\% too high at Jungfraujoch. Thus on the basis of two continental sites, it appears that we have about $50 \%$ too much $\mathrm{SO}_{2}$ and sulfate in the free troposphere.

In order to assess the model performance in the mid to upper troposphere, we must rely upon comparison with aircraft observations. Such observations are problematic for a number of reasons, including their brief duration and their design to examine particular meteorological phenomena. Nevertheless, at high levels we expect relatively low variability with longitude due to more efficient zonal mixing (see e.g., Figures 4c, 4d, $5 \mathrm{c}$, and 5d). The campaigns used here include the $\mathrm{Pa}$ cific Exploratory Mission (PEM) West A (SeptemberOctober 1991), PEM West B (February-March 1993), PEM-Tropics (September-October 1996) and the NASA Subsonic Aircraft: Contrail and Cloud Effects Special Study (SUCCESS; April 1996). Figure 12 shows the regions from these campaigns that were used in the comparison. We have attempted to distinguish between relatively polluted and remote boxes for the PEM data sets. In general, however, the distinction applies mostly to low altitudes. Figure 13 shows comparison of 
Table 5. Model Versus Observed Surface Concentrations

\begin{tabular}{|c|c|c|}
\hline \multirow[t]{2}{*}{ Site/Region } & \multicolumn{2}{|c|}{ Concentration, ppt } \\
\hline & & Model \\
\hline \multicolumn{3}{|c|}{ Sulfate } \\
\hline Europe (31) & 1413 & 1058 \\
\hline Northern Europe ${ }^{a}(42)$ & 1083 & 728 \\
\hline Eastern United States (43) & 1310 & 1436 \\
\hline Canada (17) & 742 & 813 \\
\hline Oceanic, $\mathrm{NH}^{\mathrm{b}}(8)$ & 225 & 106 \\
\hline Oceanic, $\mathrm{SH}^{\mathrm{c}}(4)$ & 80 & 42 \\
\hline Antarctica $^{\mathrm{d}}(3)$ & 25 & 90 \\
\hline \multicolumn{3}{|c|}{$\mathrm{SO}_{2}$} \\
\hline Europe (31) & 4064 & 6138 \\
\hline Northern Europe ${ }^{a}(42)$ & 2746 & 5493 \\
\hline Eastern United States (43) & 2891 & 7916 \\
\hline Canada (17) & 1569 & 4658 \\
\hline Amsterdam Island & 19 & 10 \\
\hline \multicolumn{3}{|c|}{$D M S$} \\
\hline Cape Grim & 67 & 49 \\
\hline Amsterdam Island & 112 & 38 \\
\hline \multicolumn{3}{|c|}{$M S A$} \\
\hline $\operatorname{Arctic}^{e}(2)$ & 6 & 10 \\
\hline Oceanic, $\mathrm{NH}^{\mathrm{f}}(6)$ & 8 & 4 \\
\hline Oceanic, $\mathrm{SH}^{\mathrm{B}}(4)$ & 5 & 4 \\
\hline Antarctica $^{h}(2)$ & 9 & 20 \\
\hline
\end{tabular}

Number of sites used is in parentheses. The observed values are the average over all the sites and the model values are taken over the corresponding model grid boxes. NH, Northern Hemisphere; SH, Southern Hemisphere. The observed averages are first made for each month and then averaged over the year.

${ }^{a}$ All European sites north of $50^{\circ} \mathrm{N}$.

b Belau, Guam, Mace Head, Bermuda, Barbados, Midway Island Oahu, Fanning Isand.

'American Samoa, New Caledonia, Norfolk Island, Cape Grim.

¿Palmer, Mawson, South Pole.

e Heimaey, Alert.

${ }^{f}$ Mace Head, Bermuda, Barbados, Midway Island, Oahu, Fanning Island.

gAmerican Samoa, New Caledonia, Norfolk Island, Cape Grim.

h Palmer, Mawson. model profiles with $\mathrm{SO}_{2}$ data and profiles. The profiles were made by averaging the observations and respective monthly average model grid box concentrations in each model layer. Figure 14 shows the sulfate comparisons for the same regions as used in Figure 13, as well as the comparison with SUCCESS data (only sulfate is available from this campaign). Figures 15 and 16 show DMS and $\mathrm{H}_{2} \mathrm{O}_{2}$, respectively, in two of the regions.

The model $\mathrm{SO}_{2}$ is generally lower than observed in PEM-Tropics (Figures 13a and 13b). This is likely connected to the generally low $\mathrm{S}$ levels in remote (e.g., southern) regions (see also Figures 14a, 14b, 15a, and 15b). PEM-West B shows strong transport of pollutants from Asia (during springtime), and the model does capture this. At midlevels $(4-8 \mathrm{~km})$, the model $\mathrm{SO}_{2}$ is high by $50-100 \%$ compared with the PEM-West B observations.

Results for sulfate, shown in Figure 14, parallel those for $\mathrm{SO}_{2}$. In addition we show the comparison with SUCCESS observations over North America. The model is generally too high in the Northern Hemisphere and too low compared with PEM-Tropics. One difficulty in the comparison of sulfate with aircraft observations is the possibility of losses of aerosols on inlet pipes [Huebert et al., 1990]. These losses are estimated to be as great as $50-90 \%$. Note that a $50 \%$ increase in the sulfate data would greatly improve the model agreement (in the north). One of the PEM-Tropics aircraft (the P3B) attempted to account for the inlet losses by measuring aerosol losses on the pipes and including these in the reported data (B. Huebert, personal communication, 1998). These data are indicated by triangles in Figures $14 \mathrm{a}$ and $14 \mathrm{~b}$, while data from the (generally higher-flying) DE-8 aircraft are shown by plus symbols. The P3B values do tend to be higher; however, since the two aircraft were seldom at the same locations a direct comparison is difficult.

Finally, we note that the model simulation of $\mathrm{H}_{2} \mathrm{O}_{2}$ is quite good compared with the PEM-Tropics observations shown in figure 16 , although model variability does not appear to be as high as the observed scatter indicates.

Table 6. Model Versus Observed Wet Deposition Flux

\begin{tabular}{lrr}
\hline Site/Region & \multicolumn{2}{c}{ Wet Deposition Flux, mg S/m $/ \mathbf{y r}$} \\
\cline { 2 - 3 } & Observed & Model \\
\hline Eastern United States (76) & 700 & 678 \\
Western United States (76) & 166 & 113 \\
Europe (53) & 1756 & 410 \\
Northern Europe (11) & 1378 & 393 \\
South America $^{2}(3)$ & 140 & 142 \\
Arctic $^{b}(2)$ & 18 & 48 \\
Katherine, Australia $^{\text {Oceanic Sites }}{ }^{c}(6)$ & 64 & 37 \\
& 142 & 28
\end{tabular}

See general footnote to Table 5. Model S includes both sulfate and $\mathrm{SO}_{2}$.

amazon Basin and Lake Calado, Brazil; San Carlos, Venezuela.

bye 3, Greenland; Poker Flat, Alaska.

'Bermuda, American Samoa, Amsterdam Island, New Zealand, Central Tasman

Sea, Macquarie Island, East Africa. 


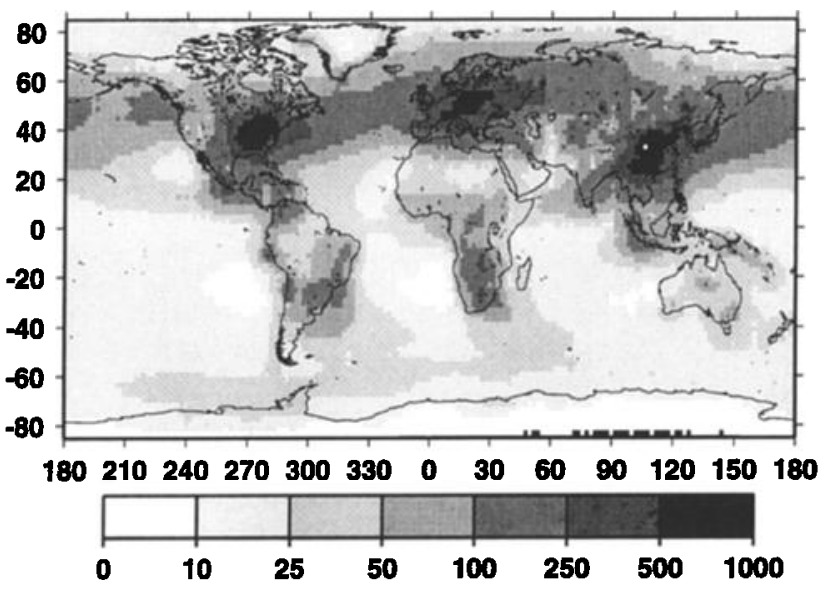

Figure 8. Model annual average sulfur wet deposition flux. Units are $\mathrm{mg} \mathrm{S} / \mathrm{m}^{2} / \mathrm{yr}$.

To summarize, all remote, low-latitude $\left(<40^{\circ}\right)$ modelobservation comparisons suggest that the natural DMS source and oxidation products of DMS are too low. At higher latitudes of the Northern Hemisphere, the picture is complicated. Surface $\mathrm{SO}_{2}$ over continents is generally quite high in the model. Over Europe sulfate is low and the deposition flux is low, suggesting need for greater oxidation. Over North America, model sulfate and deposition flux agree well with observations. At higher altitudes (of the Northern Hemisphere) there is some indication that the model $\mathrm{SO}_{2}$ and sulfate are about $50 \%$ too high. However, this conclusion is based on a very limited number of high-altitude observations.

Compared with previous models, the performance of this model at the surface is not remarkably different. Very high $\mathrm{SO}_{2}$ surface concentrations in polluted regions is common among most previous studies. An exception is Chin et al. [1996], who had lower model $\mathrm{SO}_{2}$ than other studies, possibly because this version of the GISS model had excessive convective activity over continents, which efficiently removed $\mathrm{SO}_{2}$ from the surface. The use of prognostic $\mathrm{H}_{2} \mathrm{O}_{2}$ does not improve the simulation of sulfate seasonality over North America and Europe compared with models using fixed oxidation rates or fixed $\mathrm{H}_{2} \mathrm{O}_{2}$ fields. Like most previous studies, our model tends to put a larger sulfate seasonal cycle over Europe than is observed. Kasibhatla et al. [1997] showed that adding a mechanism for heterogeneous $\mathrm{SO}_{2}$ oxidation improved the simulation over Europe by increasing the amount of wintertime oxidation relative to summer; however, this degraded the simulated seasonality over North America. Greater differences among models are expected to be seen at higher altitudes, due to the significant differences in global $\mathrm{SO}_{2}$ and sulfate burdens (see Table 2). It is difficult to compare and validate models at high altitudes, both because of sparsity of observations and because few model studies present high-altitude concentrations.

\section{Cloud Effects on Sulfate}

We now use the GCM to examine the relationship between clouds and sulfate due to in-cloud production and precipitation scavenging. (Note that we are not allowing sulfate to affect cloud properties, so that we are only looking at the effect of clouds on sulfate.) Since most (about $70 \%$ in this model) sulfate is generated by clouds, we might expect to find a positive correlation between clouds and sulfate. On the other hand, about $80 \%$ of the sulfate removal is by precipitation scavenging, which we would expect to generate negative correlation between clouds and sulfate.

Plate 2 shows temporal correlation between sulfate and cloud optical thicknesses for January and July for the full run and the natural run. Correlation coefficients are calculated from hourly time series of column sulfate mass and cloud optical thickness. Over oceans, in both the natural and full runs, correlation tends to be negative at high latitudes and positive in the tropics. Over continents, the correlation is much more positive for the full run than the natural run. This tendency persists throughout the year. Although not shown here, the same patterns occur for both convective and stratiform clouds. The positive correlation over polluted continents can be attributed to the increased availability of $\mathrm{SO}_{2}$ to make sulfate as soon as a cloud forms.

As was stated above, we are not allowing the sulfate to act as cloud condensation nuclei here. In this model the cloud droplet number concentrations are fixed at $60 \mathrm{~cm}^{-3}$ over the oceans and $100 \mathrm{~cm}^{-3}$ over the land. We might expect the correlation between cloud optical thickness and sulfate to increase if the sulfate were assumed to act as CCN.

In the following section we will explore how the cloudsulfate relationships affect the use of online instead of offline sulfate to calculate radiative forcing.

\section{Direct Radiative Forcing}

Light scattering due to the sulfate aerosol distribution in the GCM was calculated using the single gauss

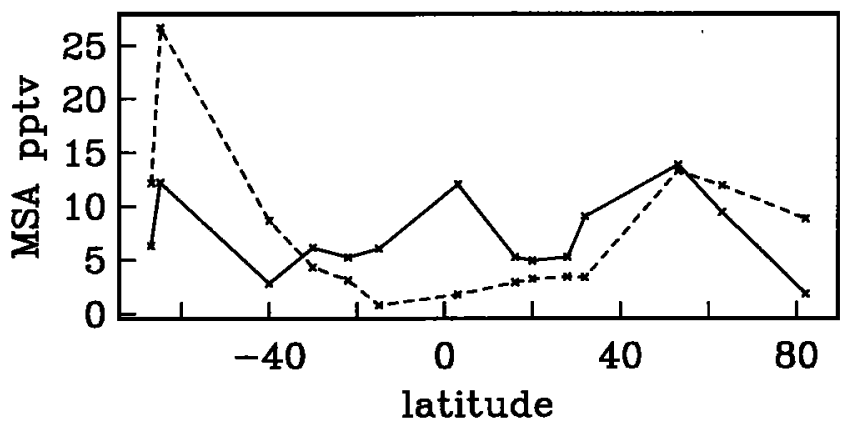

Figure 9. Annual average model versus observed MSA as a function of latitude. 

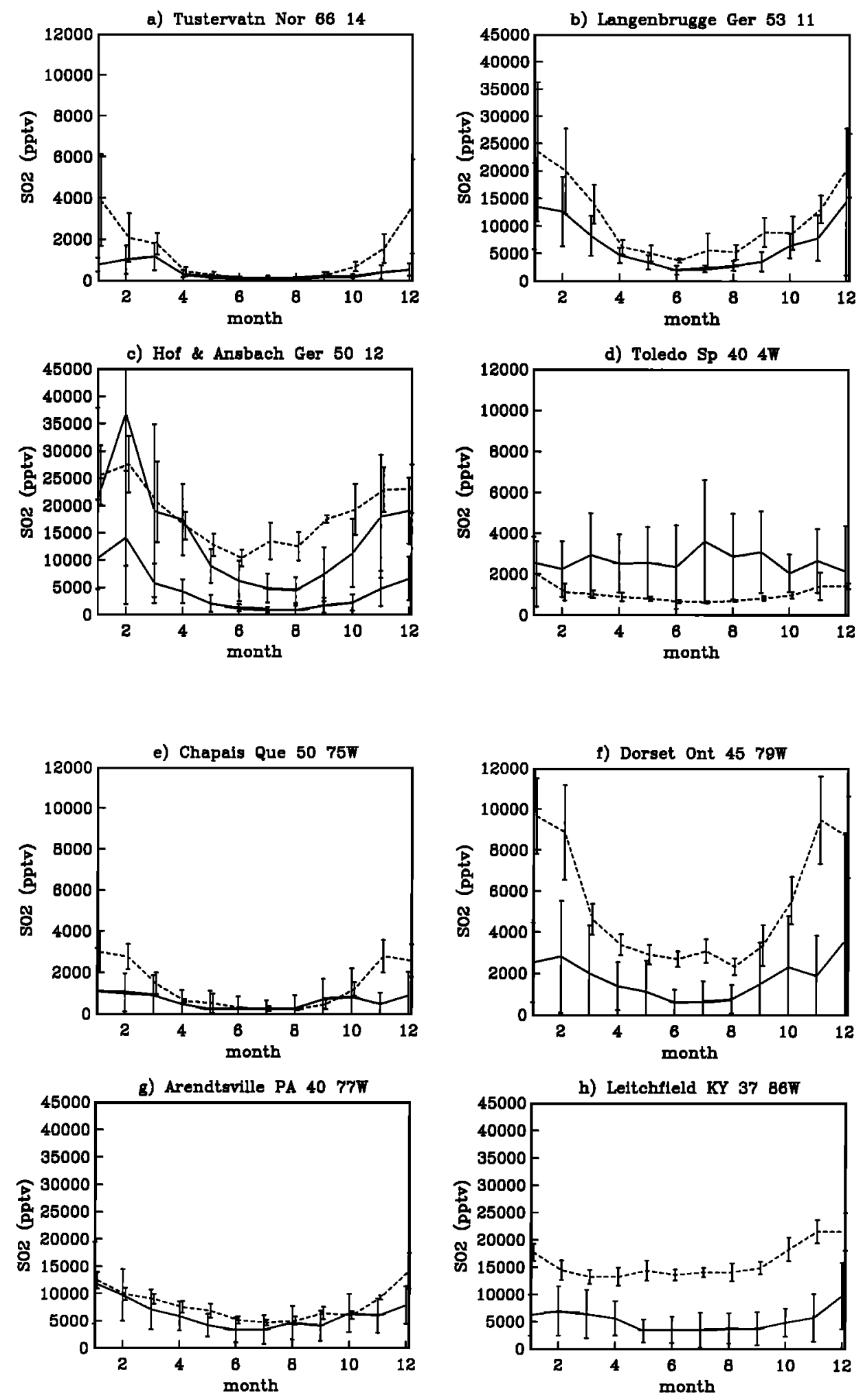

Figure 10. Comparison of modeled (dashed) and observed (solid) $\mathrm{SO}_{2}$ : (a-d) European data from EMEP and (e-h) North American data from EMEFS. Standard deviations for the model and EMEP data are based on monthly means. The standard deviations from EMEFS are based on daily averages. 

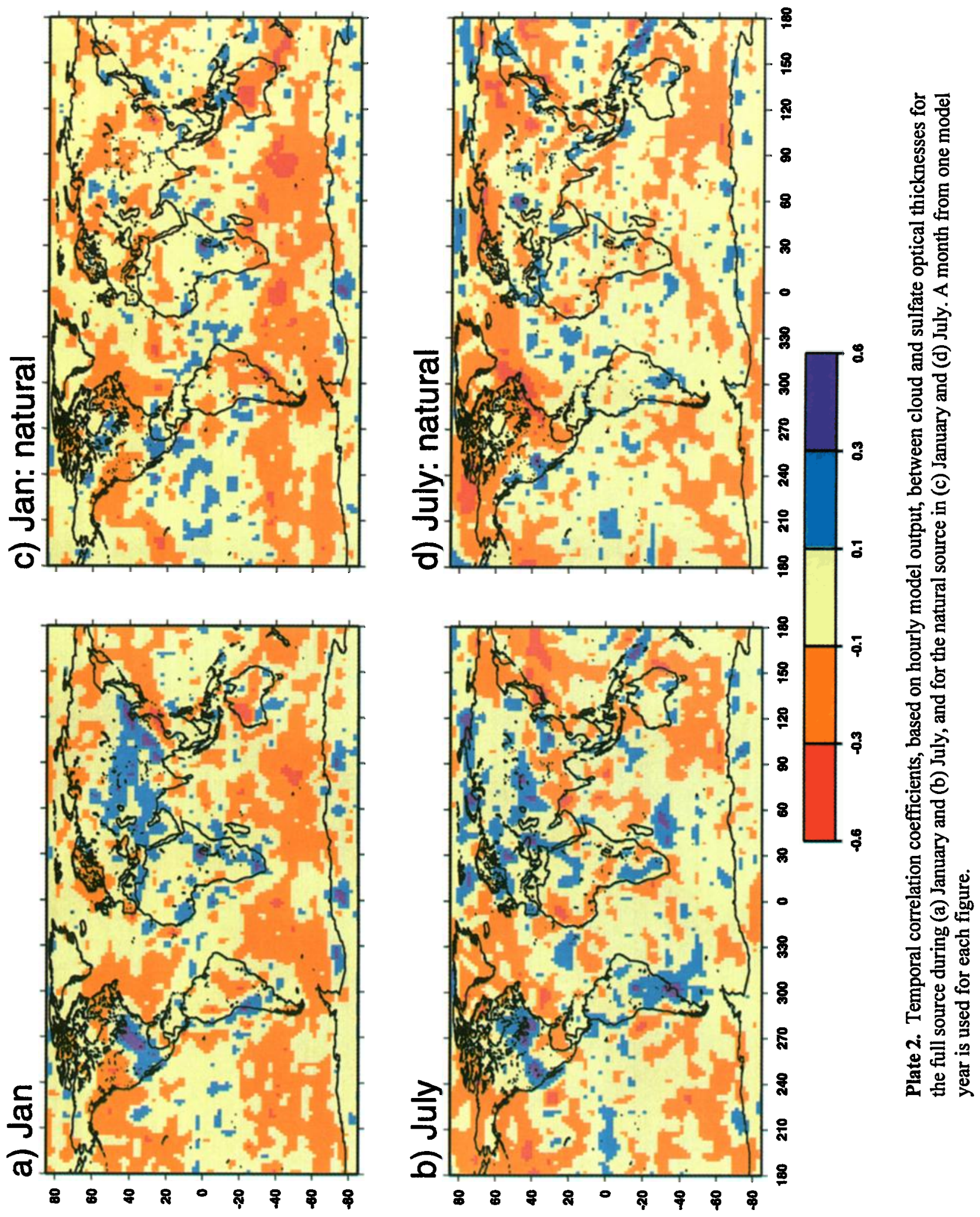

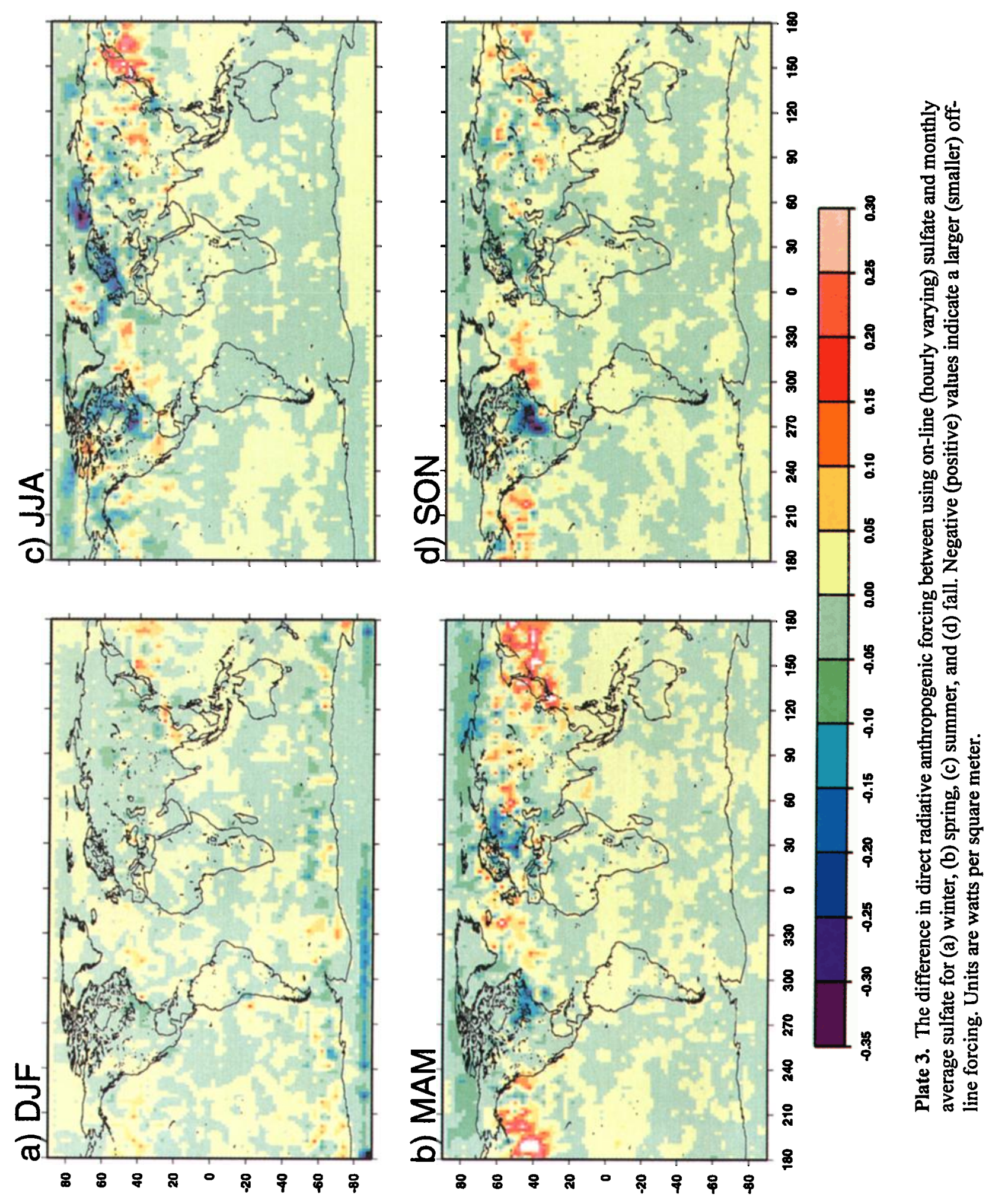

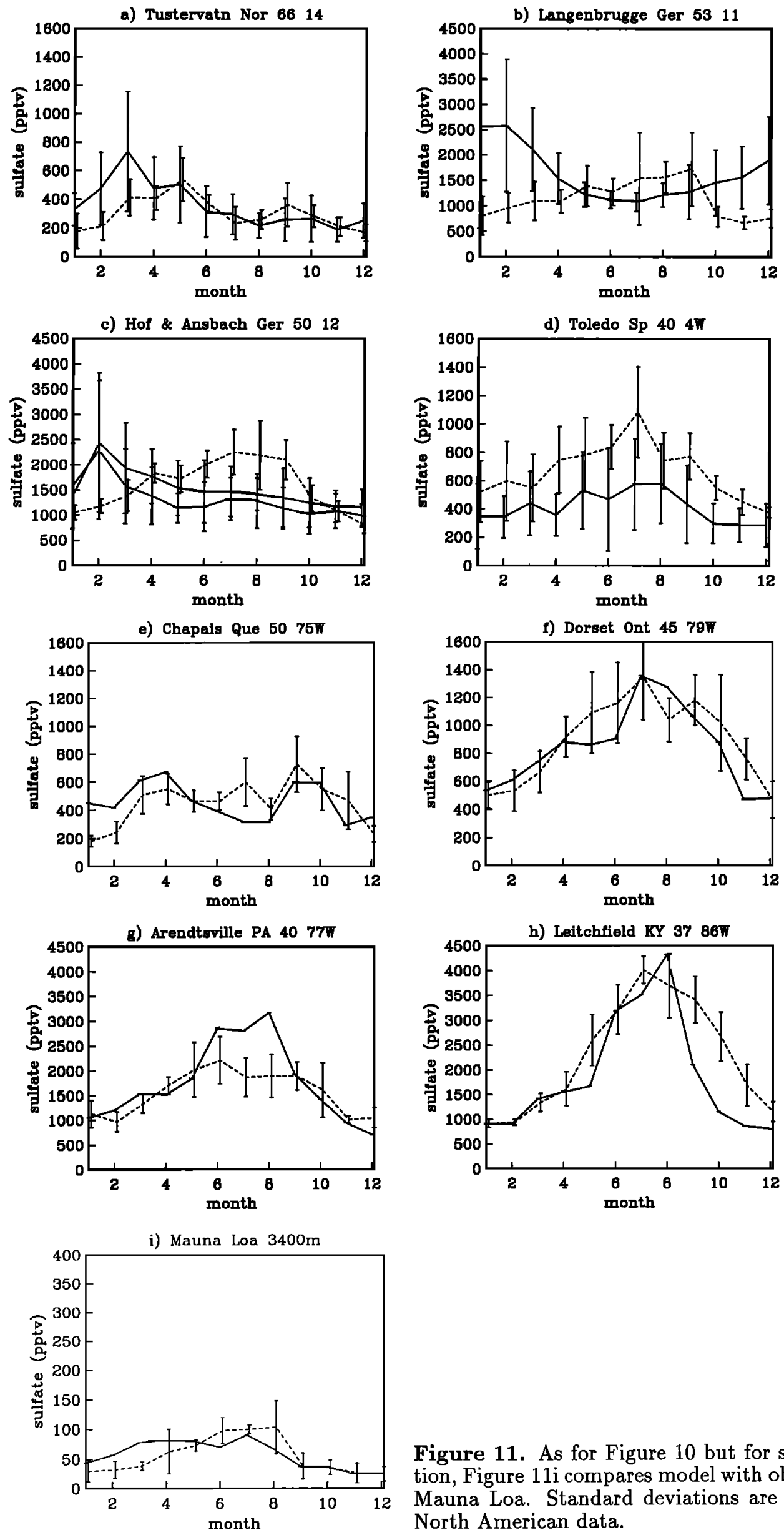

Figure 11. As for Figure 10 but for sulfate. In addition, Figure 1li compares model with observations from Mauna Loa. Standard deviations are omitted for the North American data. 


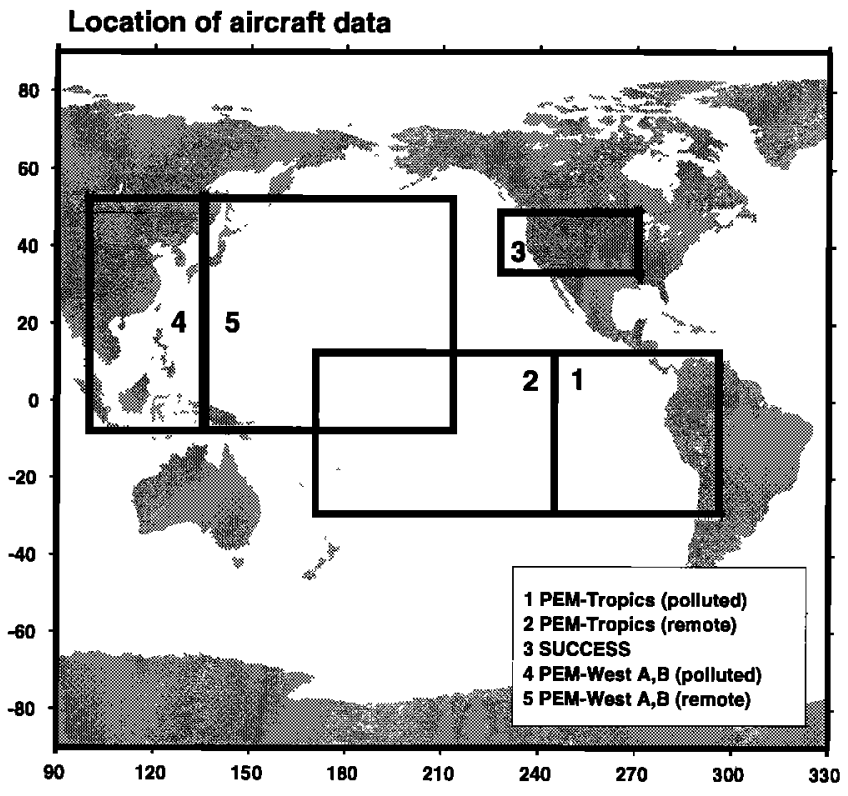

Figure 12. Locations of regions containing aircraft data shown in Figures 13-16. point doubling/adding radiative transfer model in the GISS GCM [Lacıs and Hansen, 1974; Hansen et al., 1983]. The correlated $k$ distribution method [Lacis and Ornas, 1991] is used to compute absorption by gases and particles. Six $k$ intervals were used for the spectral dependence of Mie parameters of clouds and aerosols for the solar part of the spectrum. Lacis and Oinas [1991] show that this method is accurate within $1 \%$ compared with line-by-line calculations. Sulfate radiative properties were computed using Mie scattering theory for the standard gamma size distribution with effective radius of $0.5 \mu \mathrm{m}$ and effective variance of 0.2 , for refractive indices reported by Toon et al. [1976] (see also Lacis and Mishchenko [1995]).

We calculate the $0.55 \mu \mathrm{m}$ optical thickness using the formulation of Charlson et al. [1984]: $\tau=M \alpha$, where $M$ is the sulfate mass/area $\left(\mathrm{g} / \mathrm{m}^{2}\right)$ and $\alpha=5 \mathrm{~m}^{2} / \mathrm{g} \mathrm{x}$ $f_{\mathrm{RH}}$ where $f_{\mathrm{RH}}$ accounts for the effect of relative humidity on optical thickness. The factor $f_{\mathrm{RH}}$ is equal to 1 up to relative humidities of $60 \%$ and increases gradually to 2.5 for relative humidities of $85 \%$ or more. The factor of 5 has been estimated to be appropriate for hu- a) PEMT-1

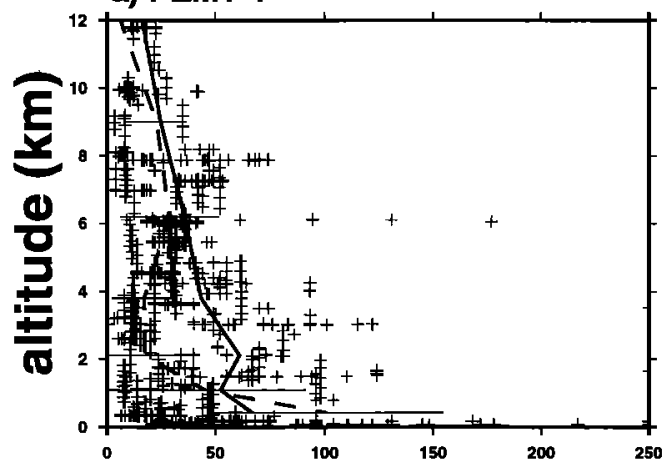

c) PWB-4

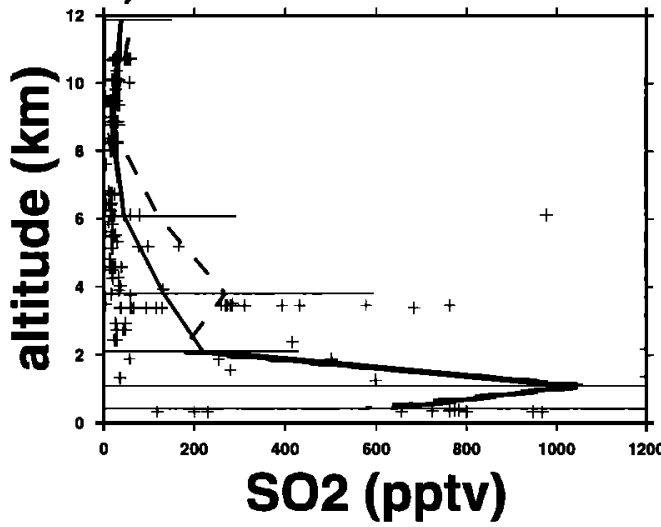

\section{b) PEMT-2}

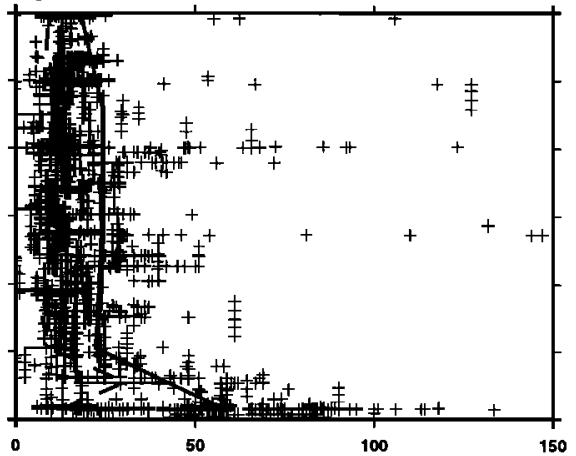

d) PWB-5

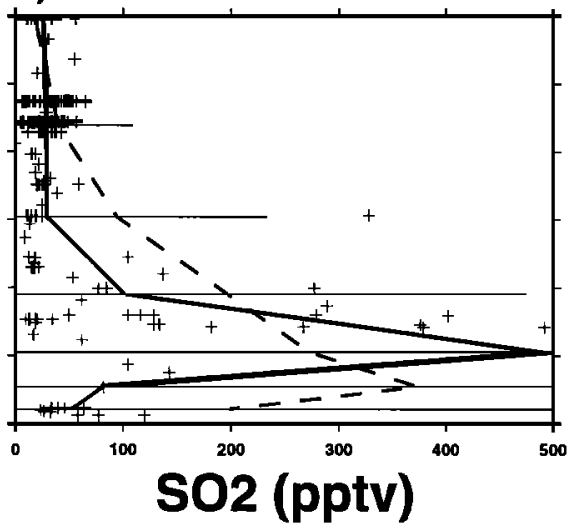

Figure 13. Comparison of modeled and observed $\mathrm{SO}_{2}$ for (a) PEM-Tropics box 1 (see figure 12), (b) PEM-Tropics box 2, (c) PEM-West B box 4, and (d) PEM-West B box 5 . The data are shown as pluses, and the mean of the data is a solid line. Data falling below the detection limit are plotted as zeros and counted as zero in calculating the mean profile. Data exceeding the upper plot bound are plotted along the right-hand side. The model values are the mean of grid boxes where data are found, and are shown by a dashed line. Model profiles are based on monthly average values for March (PEM-West B) and September (PEM-Tropics). Model standard deviation is based on hourly model variability. 
a) PEMT-1

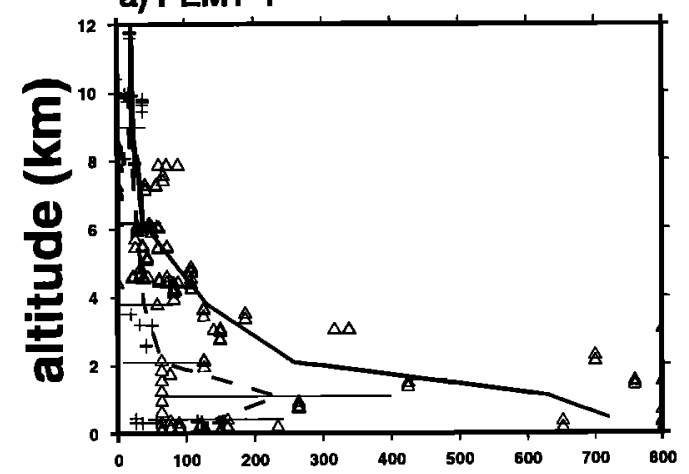

c) PWB-4

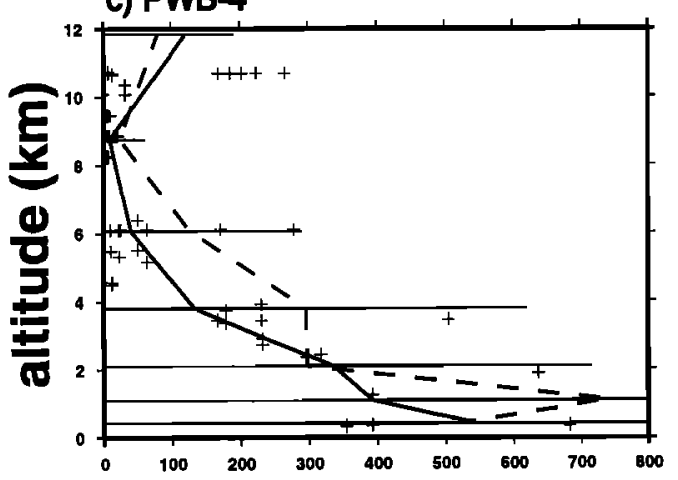

ө) SUCCESS

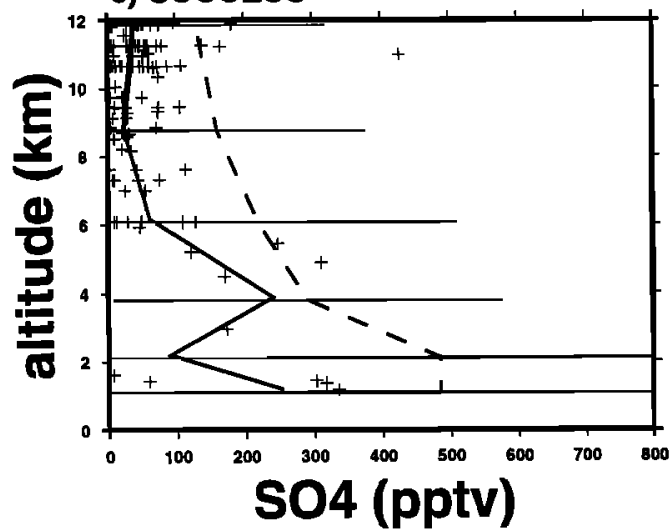

b) PEMT-2

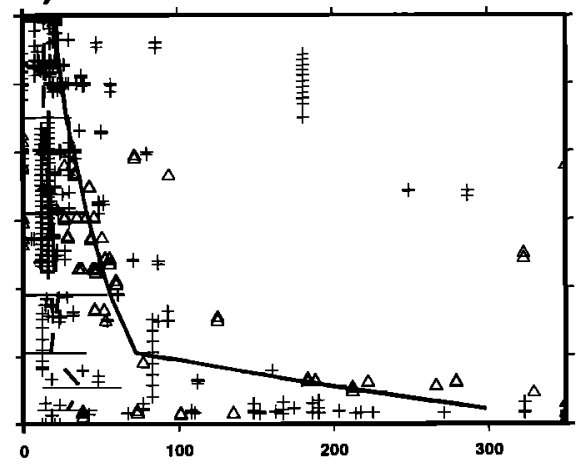

d) PWB-5

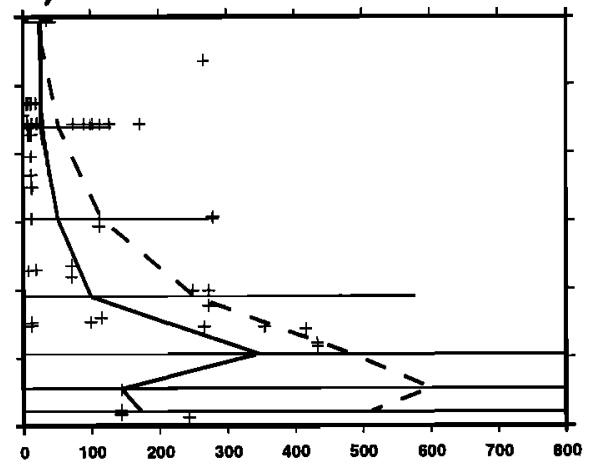

SO4 (pptv)

Figure 14. Same as for Figure 13, except for sulfate. Also shown are model and data for SUCCESS in Figure 14e. Model results for April are used for the SUCCESS comparison. For PEM-Tropics, triangles depict data from the P3B aircraft, with remaining data from the DC-8.

a) PEMT-2

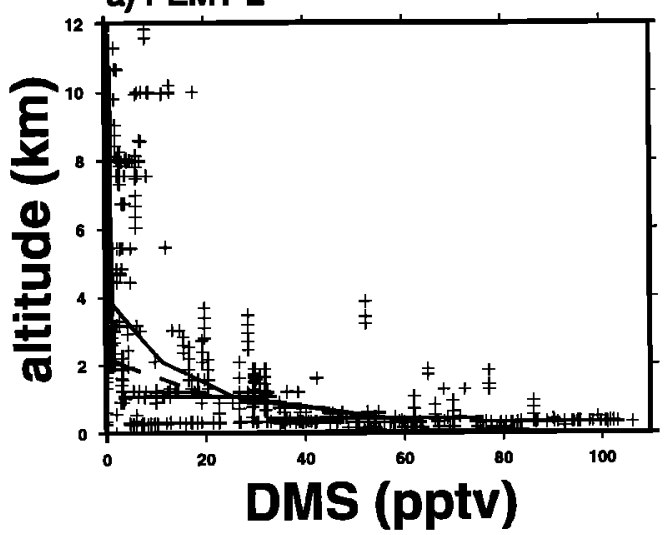

b) PWA-5

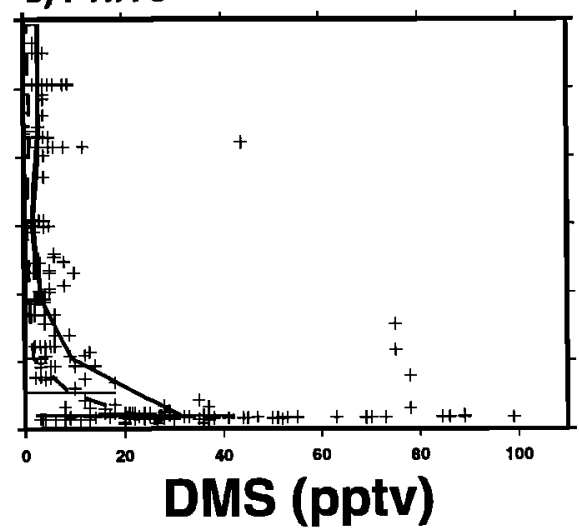

Figure 15. Comparison of modeled and observed DMS for (a) PEM-Tropics box 2, and (b) PEM-West A box 5. Profile construction is described in Figure 13. 
a) PEMT-1

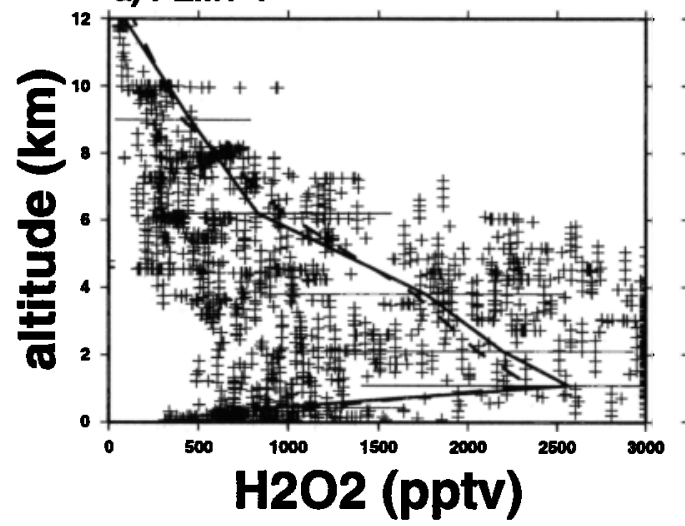

b) PEMT-2

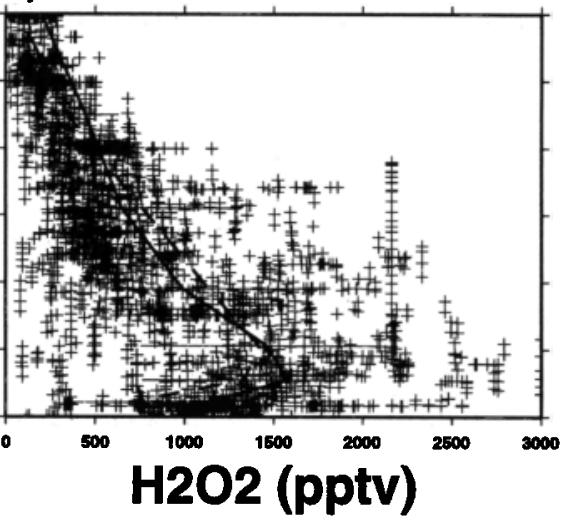

Figure 16. Comparison of modeled and observed $\mathrm{H}_{2} \mathrm{O}_{2}$ for PEM-tropics (a) box 1 and (b) box 2. Profile construction is described in Figure 13.

midities below $50 \%$ [Charlson et al., 1991]. The optical thickness is shown in Figure $17 \mathrm{a}$ and $\alpha$ is shown in Figure $17 \mathrm{~b}$. We may compare our optical thicknesses with those derived for total aerosol from advanced very high resolution radiometer (AVHRR) [Stowe et al., 1997] in the North Atlantic, where we would expect sulfate to dominate the observations. Overall, the agreement is good. Along the eastern coasts of North America and

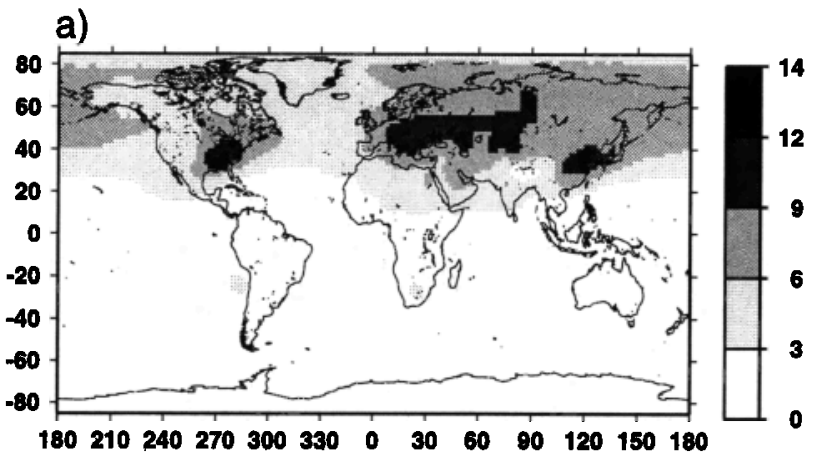

b)

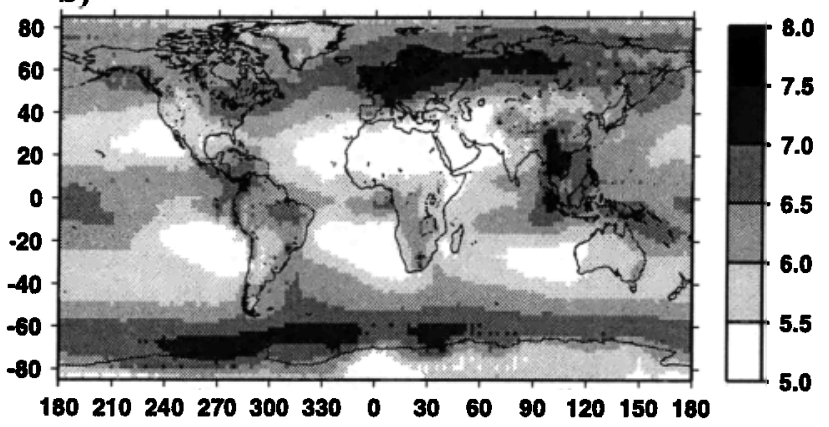

Figure 17. (a) Annual average optical thickness, $\tau \times$ 100 . The global average value is 2.69 . Optical thickness was calculated using the formulation $\tau=$ sulfate mass/area $\mathrm{x} \alpha$ where $\alpha$ (shown in b) is a factor accounting for the effect of relative humidity on optical thickness.
Asia, both observations and model have values between 0.09 and 0.12 , with values of $0.06-0.09$ extending farther eastward into the oceans. However, the observations have a band of 0.06-0.09 extending all the way across the Atlantic; it is likely that the less soluble carbonaceous aerosols contribute to this. The 0.06-0.09 band is reproduced by the model in the Pacific, but extends further north than observed.

We calculate the shortwave sulfate forcing by taking the difference at each (radiative) time step between the radiative fluxes including sulfate and not including sulfate. This is done for both full (anthropogenic plus natural) and natural runs, and the difference between the forcings is the anthropogenic forcing. The seasonally averaged results are shown in Figure 18. The annual average anthropogenic forcing is $-0.68 \mathrm{~W} / \mathrm{m}^{2}$, with a full-run forcing of $-0.91 \mathrm{~W} / \mathrm{m}^{2}$. There is strong seasonal variation in the forcing with a maximum in the summertime, when sulfate mass is also greatest. Maximum anthropogenic forcing of $-6 \mathrm{~W} / \mathrm{m}^{2}$ occurs during summertime over eastern North America, eastern Europe, and eastern Asia.

Our anthropogenic forcing value is near the high end of previous estimates. Some of these include: -0.3 $\mathrm{W} / \mathrm{m}^{2}$ (Kiehl and Rodhe [1995], Boucher and Anderson [1995], and Kiehl and Briegleb [1993], all using sulfate from Langner and Rodhe [1991]), $-0.35 \mathrm{~W} / \mathrm{m}^{2}$ [Feichter et al., 1997], -.4 W/m² (Chuang et al. [1997] and Haywood et al. [1997], using sulfate from Langner and Rodhe [1991]), $-0.6 \mathrm{~W} / \mathrm{m}^{2}$ (Charlson et al. [1991] using sulfate from Langner and Rodhe [1991]), $-0.66 \mathrm{~W} / \mathrm{m}^{2}$ (Kiehl and Rodhe [1995] using sulfate from Pham et al. [1995], $-0.82 \mathrm{~W} / \mathrm{m}^{2}$ (Haywood and Ramaswamy [1998] using sulfate from Kasibhatla et al. [1997]) and -0.9 $\mathrm{W} / \mathrm{m}^{2}$ [Taylor and Penner, 1994]. Two versions of the Langer and Rodhe [1991] model are used in the above studies, the "standard" case (which is used in Table 2), and the "slow oxidation" case, which has a lower sulfate burden of $0.55 \mathrm{Tg} \mathrm{S} / \mathrm{yr}$. There is no particular trend among the studies using these two versions, i.e., the 
a) DJF

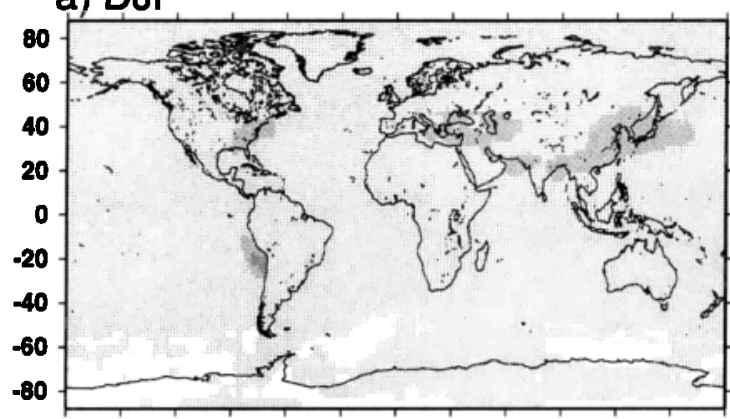

b) MAM

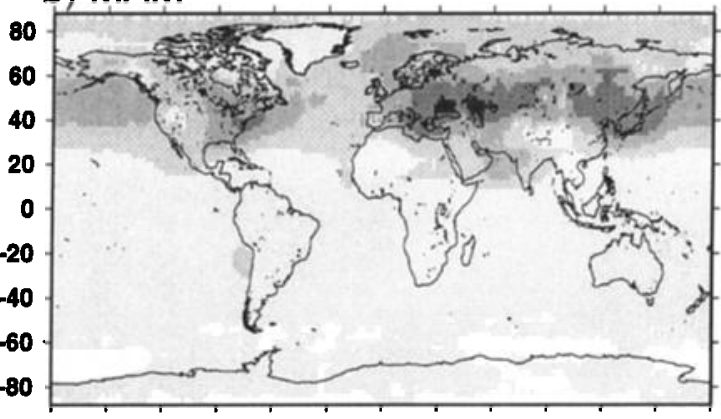

$180210240270300330 \quad 0 \quad 30 \quad 60 \quad 90 \quad 120150 \quad 180180210240270300 \quad 330 \quad 0 \quad 30 \quad 60 \quad 90 \quad 120150180$

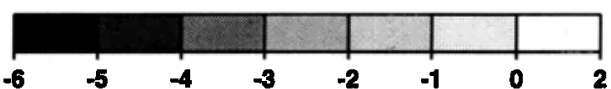

Figure 18. Direct shortwave anthropogenic sulfate radiative forcing $\left(\mathrm{W} / \mathrm{m}^{2}\right)$. Global average values are (a) winter: $-0.32 \mathrm{~W} / \mathrm{m}^{2}$, (b) spring $-0.76 \mathrm{~W} / \mathrm{m}^{2}$, (c) summer: $-0.99 \mathrm{~W} / \mathrm{m}^{2}$, and (d) fall: $-0.66 \mathrm{~W} / \mathrm{m}^{2}$. ones using the slow oxidation input do not necessarily have lower forcing. In addition to the sulfate burden, some other factors that influence the forcing include the formulation for optical parameters, how these parameters vary with relative humidity, the radiative transfer scheme, and other GCM properties such as clouds and relative humidity.

One way to distinguish the impacts of the sulfate model and the radiative implementation is to use the normalized forcing of Boucher and Anderson [1995] and Nemesure et al. [1995], which normalizes forcing by the anthropogenic sulfate burden. In Table 7 we list several studies that provide the information needed for this cal- c) JJA

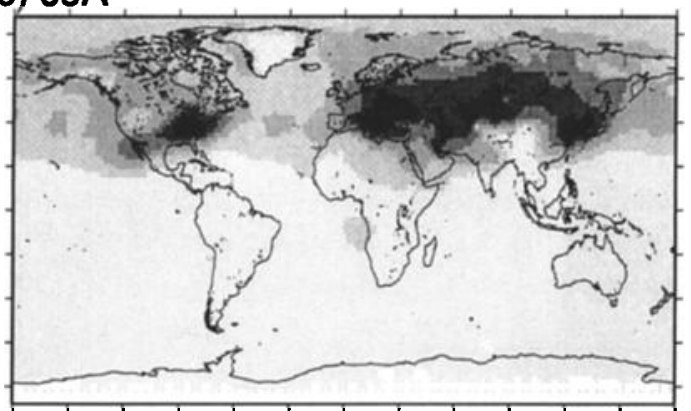

d) SON

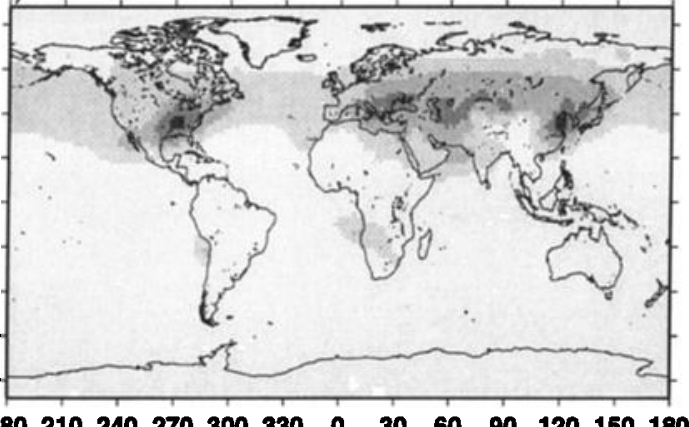

culation. From the table we can see that our model has a significantly higher anthropogenic burden (although our total sulfate burden is not high compared with the other models, the natural contribution is lower). The normalized forcing (which expresses the effects of the remaining radiative influences) is within the range of the other studies. Kiehl and Briegleb [1993] attributed the larger forcing of Charlson et al. [1991] to their lack of dependence of the specific extinction on wavelength. Much of the differences amongst the models in Table 7 may be attributed to the dependence of scattering efficiency, or optical thickness, on relative humidity. Kiehl and Briegleb [1993] used an approach identical to

Table 7. Normalized Anthropogenic Sulfate Forcing

\begin{tabular}{lccc}
\hline Study & $\begin{array}{c}\text { Anthropogenic Sulfate } \\
\text { Burden, mg sulfate } / \mathrm{m}^{2}\end{array}$ & $\begin{array}{r}\text { Direct Forcing (NH), } \\
\text { W } / \mathrm{m}^{2}\end{array}$ & $\begin{array}{c}\text { Normalized } \\
\text { Forcing, W/g }\end{array}$ \\
\hline Haywood and Ramaswamy [1998] & & & $-0.82(-1.40)$ \\
This study & 1.8 & $-0.68(-1.22)$ & -460 \\
Charlson et al. [1991] & 3.3 & $-0.60(-1.07)$ & -200 \\
Feichter et al. [1997] & 2.0 & $-0.35(-0.55)$ & -300 \\
Boucher and Anderson [1995] & 2.2 & $-0.30(-0.47)$ & -160 \\
Kiehl and Briegleb [1993] & 2.3 & $-0.28(-0.43)$ & -160 \\
\end{tabular}


our own. Feichter et al. [1997] used a constant value of $\alpha=5$, while Charlson et al. [1991] used a constant value of $\alpha=8.5$. Boucher and Anderson [1995] and Haywood and Ramaswamy [1998] used Mie theory to determine the dependence on relative humidity of scattering efficiency as well as the backscatter fraction. Boucher and Anderson [1995] argue that these relative humidity dependences compensate to some extent. Haywood and Ramaswamy [1998] attribute their large forcing to the use of average solar zenith angle in the Geophysical Fluid Dynamics Laboratory model, and to the difference between the Kasibhatla et al. [1997] and Langner and Rodhe [1991] sulfate seasonalities and vertical distributions and how these interact with relative humidity.

Since most previous radiative forcing calculations are based on monthly average sulfate values from chemical transport models, we want to compare the forcings based on on-line sulfate and off-line (monthly average) sulfate. For the comparison, we saved 3-D monthly average sulfate mass for 1 year and used these as off-line inputs to calculate sulfate optical thickness in a separate simulation. The difference between the on-line and off-line sulfate radiative forcings was taken hourly and averaged over each month. The global, annual average difference is close to zero, as was also found by Feichter et al. [1997]. However, on a seasonal and regional basis, there are some significant differences, as shown in Plate 3 . The negative values in Plate 3 indicate that the forcing based on the monthly average sulfate is greater and the positive values indicate that the forcing due to the hourly varying sulfate is greater. It is not unusual for the differences to be as much as $\pm 5-10 \%$ relative to the full-run forcing.

If we compare the DJF (Plate 3a) and JJA (Plate 3c) with January and July in Plate $2 \mathrm{a}$ and $2 \mathrm{~b}$, respectively, we see that in many cases the monthly average forcing exceeds the on-line forcing in the same regions where cloud-sulfate correlation is high (e.g., eastern North America and northern Europe, the southern North Sea), and the monthly average forcing is less than the on-line forcing in regions where the cloud-sulfate correlation is negative (e.g., the northern oceans). This is expected, since in regions where cloud-sulfate correlation is high, a monthly average sulfate optical thickness would be too large during times when cloud cover is low. Conversely, in regions of negative correlation, monthly average sulfate would not be large enough during times of low cloud cover. Thus in general, using off-line sulfate will tend to overestimate sulfate forcing in polluted regions.

\section{Conclusions}

We have performed a tropospheric sulfur simulation in the GISS GCM that includes the in-cloud oxidant $\mathrm{H}_{2} \mathrm{O}_{2}$ as a prognostic species. The model has anthropogenic $\mathrm{SO}_{2}$ burden and anthropogenic sulfate radiative forcing which are near the high end of previous investigations.
The large $\mathrm{SO}_{2}$ burden, as also found and discussed by Roelofs et al. [1998], results primarily from the depletion of prognostic $\mathrm{H}_{2} \mathrm{O}_{2}$. Previous studies that used off-line in-cloud oxidant fields assumed complete replacement of the oxidant in each time step. Since $\mathrm{H}_{2} \mathrm{O}_{2}$ requires 1 to 2 days to replenish itself, there is less prognostic $\mathrm{H}_{2} \mathrm{O}_{2}$ available to oxidize $\mathrm{SO}_{2}$ and hence a higher $\mathrm{SO}_{2}$ burden. Indeed our $\mathrm{SO}_{2}$ burden is similar to the other models having prognostic $\mathrm{H}_{2} \mathrm{O}_{2}$ [Lelieveld et al., 1997; Roelofs et al., 1998]. A second factor responsible for the large $\mathrm{SO}_{2}$ burden is that $\mathrm{SO}_{2}$ is not completely oxidized in polluted regions and significant amounts are transported to the relatively dry free troposphere by moist convection. Both $\mathrm{H}_{2} \mathrm{O}_{2}$ depletion and $\mathrm{SO}_{2}$ transport by convection vary seasonally, with the greatest effect during winter.

We have compared our model with previous models and with available observations. Near the surface, our model performs similarly to many previous simulations. The surface sulfate simulation is good, particularly in North America where both magnitude and seasonality are well reproduced. However, as in previous studies, the surface $\mathrm{SO}_{2}$ concentrations are higher than those observed in polluted regions, typically by a factor of 2 or more, with largest biases at high latitudes during winter. Also, the model sulfate in Europe is too high during summer and too low during winter. As was discussed by Kasibhatla et al. [1997], some of these difficulties would be alleviated by addition of a heterogeneous oxidation mechanism. In the case of our model, similar to theirs, such a mechanism is likely to improve the simulation in Europe but would degrade the simulation in North America.

A consequence of the high $\mathrm{SO}_{2}$ burden in this model is that a greater proportion of sulfate production occurs by dry oxidation (in the free troposphere), compared with previous models. This generates higher sulfate concentrations in the free troposphere than is the case in many previous models (although our global average burden is typical). On the basis of very sparse data, it appears that our model sulfate may be about $50 \%$ too high in the free troposphere of polluted regions. More high-altitude data are required to better validate this as well as other models.

Compared with previous studies and observations in remote regions, our natural source is low. We are using a new DMS source which is based on a very large DMS surface water concentration data base [Kettle et al., 1999]. This DMS, together with the commonly used Liss and Merlivat [1986] sea-to-air transfer scheme, and the somewhat sluggish GCM surface winds, results in sulfur levels in remote regions which are low compared with observations. Given the number of uncertainties in the DMS source [e.g., Chin et al., 1998], this is difficult to remedy.

We estimate a $23 \%$ natural source contribution to the total sulfate burden, an amount much lower than previously estimated in global models. This is due mostly to the large transport of anthropogenic $\mathrm{SO}_{2}$ to the free 
troposphere and to a lesser extent to the lower natural source.

We calculate an anthropogenic sulfate direct radiative forcing of $-0.67 \mathrm{~W} / \mathrm{m}^{2}$. This forcing is within the range, but near the high end, of previous estimates. This is partly because of the large anthropogenic sulfate burden in our model. Our formulation for allowing dependence of optical thickness on relative humidity may also contribute to larger forcing than in many previous studies.

Since most sulfate radiative forcing studies are based on offline sulfate fields, we compared the forcings of online and off-line sulfate. Like Feichter et al. [1997], we found little difference on a global average. However, we did find regional differences. In particular, over some polluted, continental regions, the forcing from the off-line sulfate was typically greater by $10 \%$. This appears to be related to the fact that sulfate tends to be positively correlated with clouds in these regions. If monthly average sulfate values are used for forcing calculations in such regions, excessive sulfate will be assumed during times of low cloud cover, and the sulfate forcing will be overestimated. It is precisely in these regions that the climatological study of Mitchell et al. [1995] found that temperature changes due to (off-line) sulfate and greenhouse gas forcings were lower than observed changes. Here we have shown that the use of online sulfate would improve such simulations that have too little warming over continents and too much warming over oceans, although the improvement is probably less than needed.

Acknowledgments. The EMEFS data utilized in this study were collected and prepared under the cosponsorship of the United States Environmental Protection Agency, the Atmospheric Environment Service, Canada, the Ontario Ministry of Environment, the Electric Power Research Institute, and the Florida Electric Power Coordinating Group. We thank Jack Dibb for providing sulfate data from the SUCCESS campaign. This research is funded by NASA ACMAP EOS/IDS project on Chemistry, Aerosols, and Climate ("CACTUS").

\section{References}

Atkinson, R., D. L. Baulch, R. A. Cox, R. F. Hampson Jr., J. A. Kerr, and J. Troe, Evaluated kinetic and photochemical data for atmospheric chemistry: Supplement IV, Atmos. Environ., Part A, 26, 1187-1230, 1992.

Atlas, R., R. N. Hoffman, S. C. Bloom, J. C. Jusen, and J. Ardizzone, A multiyear global surface wind velocity dataset using SSM/I wind observations, Bull. Am. Meteorol. Soc., 77, 869-882, 1996.

Bates, T. S., J. D. Cline, R. H. Gammon, and S. R. KellyHansen, Regional and seasonal variations in the flux of oceanic dimethylsulfide to the atmosphere, J. Geophys. Res., 92, 2930-2938, 1987.

Bates, T. S., B. K. Lamb, A. Guenther, J. Dignon, and R. E. Stoiber, Sulfur emissions to the atmosphere from natural sources, J. Atmos. Chem., 14, 315-337, 1992.

Baughcum, S. L., D. M. Chan, S. M. Happenny, S. C. Henderson, P. S. Hertel, T. Higman, D. R. Maggiora, and C. A. Oncina, Emissions scenarios development: Scheduled 1990 and projected 2015 subsonic, Mach 2.0 and Mach 2.4 aircraft, in The Atmospheric Effects of Stratospheric Aircraft: A Third Program Report, NASA RF. Publ., 1313, 89-131, Nov. 1993.

Benkovitz, C. M., M. T. Scholtz, J. Pacyna, L. Tarrason, J. Dignon, E. C. Voldner, P. A. Spiro, J. A. Logan, and T. E. Graedel, Global gridded inventories of anthropogenic emissions of sulfur and nitrogen, J. Geophys. Res., 101 29,239-29,253, 1996.

Boucher, O. and T. L. Anderson, General circulation model assessment of the sensitivity of direct climate forcing by anthropogenic sulfate aerosols to aerosol size and chemistry, J. Geophys. Res., 100, 26,117-26,134, 1995.

Charlson, R. J., D. S. Covert, and T. V. Larson, Observation of the effect of humidity on light scattering by aerosols, in Hygroscopic Aerosols, edited by L. Ruhnke and A. Deepak, pp. 35-44, A. Deepak, Hampton, Va., 1984.

Charlson, R. J., J. Langner, H. Rodhe, C. B. Leovy, and S. G. Warren, Perturbation of the northern hemisphere radiative balance by backscattering from anthropogenic sulfate aerosols, Tellus, Ser. $A B, 43,152-163,1991$.

Chin, M., and D. J. Jacob, Anthropogenic and natural contributions to tropospheric sulfate: A global model analysis, J. Geophys. Res., 101, 18,691-18,699, 1996.

Chin, M., D. J. Jacob, G. M. Gardner, M. S. ForemanFowler, P. A. Spiro, and D. L. Savoie, A global threedimensional model of tropospheric sulfate, J. Geophys. Res., 101, 18,667-18,690, 1996.

Chin, M., R. B. Rood, D. J. Allen, M. O. Andreae, A. M. Thompson, S.-J. Lin, R. M. Atlas, and J. V. Ardizzone, Processes controlling dimethylsulfide over the ocean: Case studies using a 3-D model driven by assimilated meteorological fields, J. Geophys. Res., 103, 8341-8353, 1998.

Chuang, C. C., J. E. Penner, K. E. Taylor, A. S. Grossman, and J. J. Walton, An assessment of the radiative effects of anthropogenic sulfate, J. Geophys. Res., 102, 3761-3778, 1997.

Dana, M. T. and J. M. Hales, Statistical aspects of the washout of polydisperse aerosols, Atmos. Environ., 10, 45-50, 1976.

Del Genio, A. D. and M.-S. Yao, Efficient cumulus parameterization for long-term climate studies: The GISS scheme, in The Representation of Cumulus Convection in Numerical Models, Monogr. 46, edited by K. A. Emanuel and D. J. Raymond, pp. 181-184, Am. Meteorol. Soc., Boston, Mass., 1993.

Del Genio, A. D., M.-S. Yao, W. Kovari, and K. K.-W Lo, A prognostic cloud water parameterization for global climate models, J. Clim., 9, 270-304, 1996.

Dentener, F. J., and P. J. Crutzen, Reaction of $\mathrm{N}_{2} \mathrm{O}_{5}$ on tropospheric aerosols: Impact on the global distributions of $\mathrm{NO}_{x}, \mathrm{O}_{3}$ and $\mathrm{OH}, J$. Geophys. Res., 98, 7149-7163, 1993.

Feichter, J., E. Kjellstrom, H. Rodhe, F. Dentener, J. Lelieveld, and G.-J. Roelofs, Simulation of the tropospheric sulfur cycle in a global climate model, Atmos. Environ., 30, 1693-1707, 1996.

Feichter, J., U. Lohmann, and I. Schult, The atmospheric sulfur cycle in ECHAM-4 and its impact on the shortwave radiation, Clim. Dyn., 13, 235-246, 1997.

Giorgi, F., and W. L. Chameides, Rainout lifetimes of highly soluble aerosols and gases as inferred from simulations with a general circulation model, J. Geophys. Res., 91, 14,367-14,376, 1986.

Glantz, P., E. Kjellström, and J. Feichter, Evaluation of the Dimethylsulphide distribution in the ECHAM model, Rep. CM-92, Dep. of Meteorol. Stockholm Univ., Stockholm, 1997.

Hansen, J., G. Russell, D. Rind, P. Stone, A. Lacis, S. Lebedeff, R. Ruedy, and L. Travis, Efficient three-dimensional 
global models for climate studies: Models I and II, Mon. Weather Rev., 111, 609-662, 1983.

Haywood, J. M., and V. Ramaswamy, Global sensitivity of the direct radiative forcing due to anthropogenic sulfate and black carbon aerosols, J. Geophys. Res., 103, 6043$6058,1998$.

Haywood, J. M., D. L. Roberts, A. Slingo, J. M. Edwards, and K. P. Shine, General circulation model calculations of the direct radiative forcing by anthropogenic sulfate and fossil-fuel soot aerosol, J. Clim., 10, 1562-1577, 1997.

Huebert, B. J., G. Lee, and W. L. Warren, Airborne aerosol inlet passing efficiency measurement, J. Geophys. Res., 95, 16,369-16,381, 1990.

Horowitz, L. W., J. Liang, G. M. Gardner, and D. J. Jacob, Export of reactive nitrogen from North America during summertime: Sensitivity to hydrocarbon chemistry, $J$. Geophys. Res., 103, 13,451-13,476, 1998.

Jacob, D. J., Chemistry of $\mathrm{OH}$ in remote clouds and its role in the production of formic acid and peroxymonosulfate, J. Geophys. Res., 91, 9807-9826, 1986.

Kasibhatla, P., W. L. Chameides, and J. St. John, A threedimensional global model investigation of the seasonal variation in the atmospheric burden of anthropogenic sulfate aerosols, J. Geophys. Res., 102, 3737-3759, 1997.

Kettle, A. J., et al., A global database of sea surface dimethylsulfide (DMS) measurements and a procedure to predict sea surface DMS as a function of latitude, longitude and month, Global Biogeochem. Cycles, 13, 394-444, 1999.

Kiehl, J. T., and B. P. Briegleb, The relative roles of sulfate aerosols and greenhouse gases in climate forcing, Science, 260, 311-314, 1993.

Kiehl, J. T., and H. Rodhe, Modeling geographical and seasonal forcing due to aerosols, in Aerosol Forcing of Climate, edited by R. J. Charlson and J. Heintzenberg, pp. 281-296, John Wiley, New York, 1995.

Koch, D. M., D. J. Jacob, and W. C. Graustein, Vertical transport of aerosols in the troposphere as indicated by ${ }^{7} \mathrm{Be}$ and ${ }^{210} \mathrm{~Pb}$ in a chemical tracer model, J. Geophys. Res., 101, 18,651-18,666, 1996.

Lacis, A. A., and J. E. Hansen, Parameterization for the absorption of solar radiation in the Earth's atmosphere, J. Atmos. Sci., 31, 118-133, 1974.

Lacis, A. A., and M. I. Mishchenko, Climate forcing, climate sensitivity, and climate response: A radiative modeling perspective on atmospheric aerosols, in Aerosol Forcing of Climate, edited by R. J. Charlson and J. Heintzenberg, pp. 11-42, John Wiley, New York, 1995.

Lacis, A. A., and V. Oinas, A description of the correlated $k$-distribution method for modeling non-gray gaseous absorption, thermal emission, and multiple scattering in vertically inhomogeneous atmospheres, J. Geophys. Res., 96, 9027-9064, 1991.

Langner, J., and H. Rodhe, A global three-dimensional model of the tropospheric sulfur cycle, J. Atmos. Chem., 13, 225-263, 1991.

Lelieveld, J., G.-J. Roelofs, L. Ganzeveld, J. Feichter, and H. Rodhe, Terrestrial sources and distribution of atmospheric sulfur, Philos. Trans. R. Soc. London, Ser. B, 352, 149158, 1997.

Liss, P. S., and L. Merlivat, Air-sea gas exchange rates: Introduction and synthesis, in The Role of Air-Sea Exchange in Geochemical Cycling, pp. 113-127, D. Reidel, Norwell, Mass., 1986.

McNaughton, D. J., and R. J. Vet, Eulerian model evaluation field study (EMEFS): A summary of surface network measurments and data quality, Atmos. Environ., 30, 227238, 1996.

Mitchell, J. F. B., T. C. Johns, J. M. Gregory, and S. F. B. Tett, Climate response to increasing levels of greenhouse gases and sulfate aerosols, Nature, 376, 501-504, 1995.

Nemesure, S., R. Wagener, S. E. Schwartz, Direct shortwave forcing of climate by the anthropogenic sulfate aerosol:
Sensitivity to particle size, composition, and relative humidity, J. Geophys. Res., 100, 26,105-26,116, 1995.

Pham, M., J.-F. Muller, G. P. Brasseur, C. Granier, and G. Megie, A three-dimensional study of the tropospheric sulfur cycle, J. Geophys. Res., 100, 26,061-26,092, 1995.

Rind, D., and J. Lerner, The use of on-line tracers as a diagnostic tool in GCM model development, J. Geophys. Res., 101, 12,667-12,683, 1996.

Roelofs, G.-J., J. Lelieveld, and L. Ganzeveld, Simulation of global sulfate distribution and the influence on effective cloud drop radii with a coupled photochemistry-sulfur cycle model, Tellus, Ser. B, 50, 224-242, 1998.

Schaug, J., J. E. Hansen, K. Nodop, B. Ottar, and J. M. Pacyna, Summary report from the chemical co-ordinating center for the third phase of EMEP, EMEP/CC Rep. 3/87, 160 pp., Norw. Inst. for Air Res., Lillestrom, 1987. Spiro, P. A., D. J. Jacob, and J. A. Logan, Global inventory of sulfur emissions with $1^{\circ} \times 1^{\circ}$ resolution, J. Geophys. Res., 97, 6023-6036, 1992.

Stowe, L. L., A. M. Ignatov, and R. R. Singh, Development, validation, and potential enhancements to the secondgeneration operational aerosol product at the National Environmental Satellite, Data, and Information Service of the National Oceanic and Atmospheric Administration, $J$. Geophys. Res., 102, 16,923-16,934, 1997.

Taylor, K. E. and J. E. Penner, Response of the climate system to atmospheric aerosols and greenhouse gases, $\mathrm{Na}$ ture, 369, 734-737, 1994.

ten Brink, H.M., S.E. Schwartz, and P.H. Daum, Efficient scavenging of aerosol sulfate by liquid-water clouds, Atmos. Environ., 21, 2035-2052, 1987.

Thornton, D. C., A. R. Bandy, B. W. Blomquist, D. D. Davis, and R. W. Talbot, Sulfur dioxide as a source of condensation nuclei in the upper troposphere of the $\mathrm{Pa}$ cific Ocean, J. Geophys. Res., 101, 1883-1890, 1996.

Thornton, D. C., A. R. Bandy, B. W. Blomquist, J. D. Bradshaw, and D. R. Blake, Vertical transport of sulfur dioxide and dimethyl sulfide in deep convection and its role in new particle formation, J. Geophys. Res., 102, 28,501-28,509, 1997.

Toon, O. B., J. B. Pollack, and B. N. Khare, The optical constants of several atmospheric aerosol species: Ammonium sulfate, aluminum oxide, and sodium chloride, $J$. Geophys. Res., 81, 5733-5748, 1976.

Wang, Y., D.J. Jacob, and J.A. Logan, Global simulation of tropospheric $\mathrm{O}_{3}-\mathrm{NO}_{x}$-hydrocarbon chemistry, 1, Model formulation, J. Geophys. Res., 103, 10,713-10,726, 1998a.

Wang, Y., J.A. Logan, and D.J. Jacob, Global simulation of tropospheric $\mathrm{O}_{3}-\mathrm{NO}_{x}$-hydrocarbon chemistry, 2, Model evaluation and global ozone budget, J. Geophys. Res., 103, 10,727-10,756, 1998b.

Wang, Y., D.J. Jacob, and J.A. Logan, Global simulation of tropospheric $\mathrm{O}_{3}-\mathrm{NO}_{x}$-hydrocarbon chemistry, 3, Origin of tropospheric ozone and effects of nonmethane hydrocarbons, J. Geophys. Res., 103, 10,757-10,768, 1998c.

Wanninkhof, R., Relationship between wind speed and gas exchange over the ocean, J. Geophys. Res., 97, 7373-7382, 1992.

Wesely, M. L., and B. B. Hicks, Some factors that affect the deposition rates of sulfur dioxide and similar gases on vegetation, J. Air Pollut. Control Assoc., 27, 1110-1116, 1977.

M. Chin, Code 916, NASA Goddard Space Flight Center, Greenbelt, MD 20771.

D. Jacob, Department of Earth and Planetary Sciences, Pierce Hall, Harvard University, 29 Oxford Street, Cambridge, MA 02138.

D. Koch, D. Rind, and I. Tegen, NASA Goddard Institute for Space Studies, Columbia University, 2880 Broadway, New York, NY 10025. (email: dkoch@giss.nasa.gov)

(Received November 17, 1998; revised April 8, 1999; accepted April 13, 1999.) 